\title{
Observations and numerical simulations of the diurnal cycle of the EUROCS stratocumulus case
}

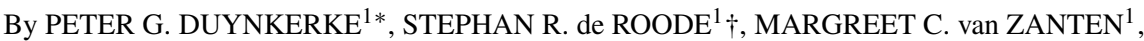 \\ JAVIER CALVO ${ }^{2}$, JOAN CUXART $^{2}$, SYLVAIN CHEINET $^{3}$, ANDREAS CHLOND $^{4}$, \\ HERVÉ GRENIER $^{5}$, PIET J. JONKER ${ }^{1}$, MARTIN KÖHLER ${ }^{6}$, GEERT LENDERINK ${ }^{7}$, \\ DAVID LEWELLEN ${ }^{8}$, CARA-LYN LAPPEN $^{9}$, ADRIAN P. LOCK ${ }^{10}$, CHIN-HOH MOENG $^{11}$, \\ FRANK MÜLLER ${ }^{4}$, DOLORES OLMEDA $^{2}$, JEAN-MARCEL PIRIOU $^{5}$, \\ ENRIQUE SÁNCHEZ ${ }^{2}$ and IGOR SEDNEV ${ }^{4}$ \\ ${ }^{1}$ Institute for Marine and Atmospheric Research, Utrecht, The Netherlands \\ ${ }^{2}$ Instituto Nacional Meteorologia, Madrid, Spain \\ ${ }^{3}$ Laboratoire de Météorologie Dynamique, Paris, France \\ ${ }^{4}$ Max-Planck Institut für Meteorologie, Hamburg, Germany \\ ${ }^{5}$ Météo-France, Toulouse, France \\ ${ }^{6}$ European Centre for Medium-Range Weather Forecasts, Reading, UK \\ ${ }^{7}$ Royal Netherlands Meteorological Institute, De Bilt, The Netherlands \\ ${ }^{8}$ West Virginia University, Morgantown, USA \\ ${ }^{9}$ Colorado State University, Fort Collins, USA \\ ${ }^{10}$ Met Office, Exeter, UK \\ ${ }^{11}$ National Center for Atmospheric Research, Boulder, USA
}

(Received 31 July 2003; revised 24 March 2004)

\section{SUMMARY}

As part of the European Project on Cloud Systems in Climate Models, the diurnal cycle of stratocumulus has been simulated with Large-Eddy Simulation (LES) models and Single Column Models (SCMs). The models were initialized and compared with observations collected in marine stratocumulus in July 1987 during the First International Satellite Cloud Climatology Project Regional Experiment. The results of the six LES models are found to be in a fair agreement with the observations. They all capture the distinct diurnal variation in the cloud liquid-water path, the turbulence profiles and clearly show a decoupled boundary layer during daytime and a vertically well-mixed boundary layer during the night. Entrainment of relatively dry and warm air from just above the inversion into the boundary layer is the major process modifying the thermodynamic structure of the boundary layer during the night. The differences that arise in the liquid-water path evolution can therefore be attributed mainly to differences in the entrainment rate. The mean entrainment rates computed from the LES model results are $0.58 \pm 0.08 \mathrm{~cm} \mathrm{~s}^{-1}$ and $0.36 \pm 0.03 \mathrm{~cm} \mathrm{~s}^{-1}$ for the night-time and daytime periods, respectively. If the horizontal domain size in a LES model is enlarged, mesoscale fluctuations develop. This leads to a broader liquidwater path distribution and a reduction of the cloud albedo.

To assess the quality of the representation of stratocumulus in general-circulation models, results from ten SCMs are compared with observations and LES results. The SCM latent and sensible heat fluxes at the surface agree fairly well with the LES results. Many of the SCMs predict a liquid-water path which is much too low, a cloud cover smaller than unity, and cloud tops that are lower than the observations and the LES results. This results in a much larger amount of downwelling short-wave radiation absorbed at the sea surface. Improvement of entrainment parametrizations is needed for a better representation of stratocumulus in SCMs.

Observations and LES results of entrainment rates for different stratocumulus cases are compared. The observed entrainment rates in Atlantic stratocumulus clouds during the Atlantic Stratocumulus Transition Experiment (ASTEX) are larger than for the ones over the Pacific Ocean off the coast of California. Results from LES models corroborate these findings. The differences in the entrainment rate can likely be attributed to the smaller inversion jumps of the liquid-water potential temperature for the ASTEX stratocumulus cases.

KEYWORDS: Cloudy boundary layers FIRE I Large-eddy simulation Single-column models

\section{INTRODUCTION}

The presence of a stable temperature inversion at the top of the atmospheric boundary layer and the availability of sufficient moisture are the major ingredients for the formation and maintenance of stratocumulus clouds. For these reasons, extended marine

\footnotetext{
* Deceased 19 January 2002

$\dagger$ Corresponding author: Institute for Marine and Atmospheric Research, Princetonplein 5, 3584 CC Utrecht, The Netherlands. e-mail: roode@ phys.uu.nl

(c) Royal Meteorological Society, 2004. A. P. Lock's contribution is Crown copyright.
} 


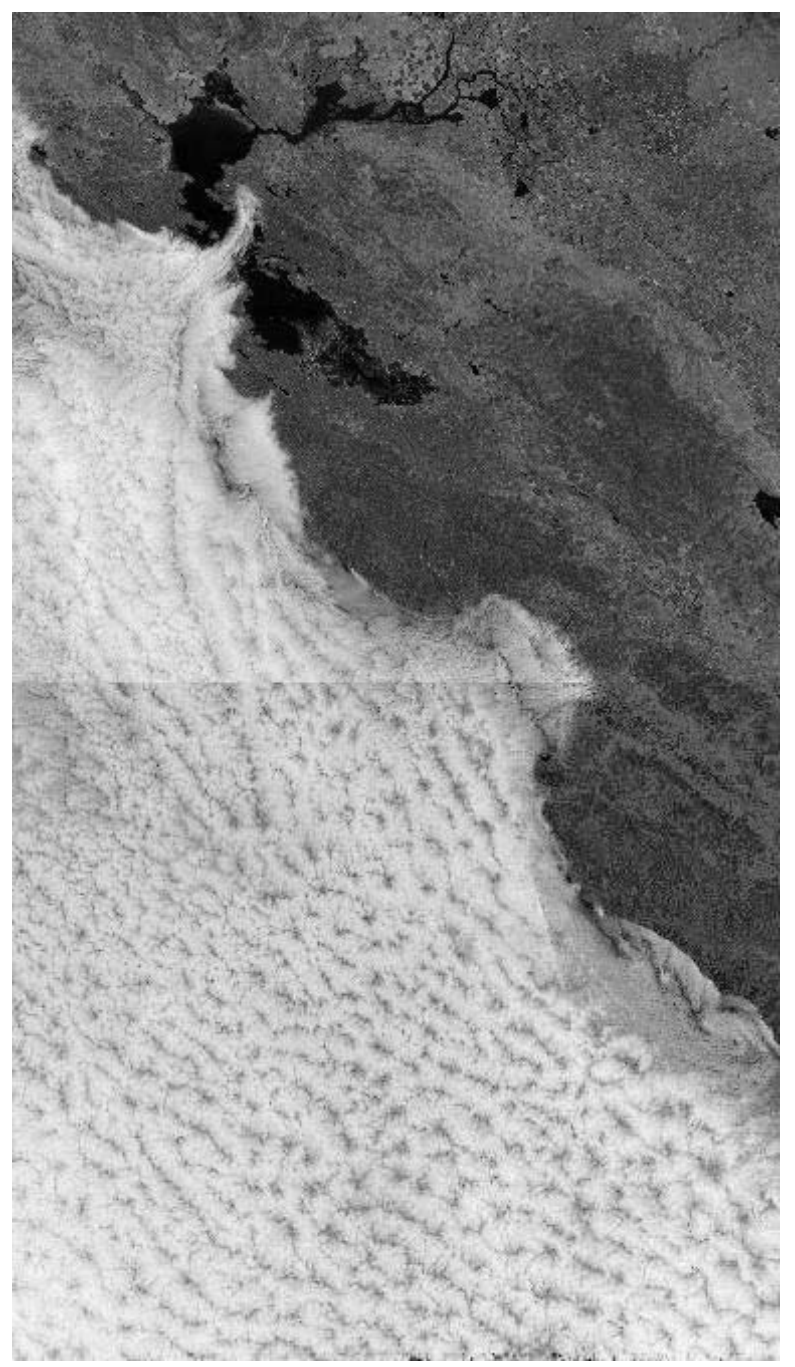

Figure 1. Landsat satellite image (horizontal area about $200 \times 400 \mathrm{~km}^{2}$ ) showing stratocumulus off the coast of California for 14 July 1987. The cloud tops are at about 500-1000 m, whereas the convective cells have a horizontal dimension of about $10 \mathrm{~km}$. The stratocumulus case studied in this paper is based on observations performed during FIRE I in the cloud deck shown.

stratocumulus-topped boundary layers (STBLs) are often found above the subtropical oceans in the descending branches of the Hadley circulation (Klein and Hartmann 1993; Norris 1997a,b). Figure 1 shows a striking example of a solid stratocumulus deck above the Pacific Ocean off the coast of California, and clear skies over the continent. Due to its high albedo, stratocumulus clouds strongly diminish the solar insolation of the earth's surface during daytime. On the other hand, stratocumulus clouds are often sufficiently optically thick such that long-wave radiation is emitted as a black body just like the underlying ocean surface. These radiative properties make stratocumulus an important factor in determining the earth's surface energy balance.

In atmospheric general-circulation models (GCMs), however, the amount of subtropical marine stratocumulus is usually underpredicted, even when the observed sea 
surface temperatures (SSTs) are prescribed (Jakob 1999). Duynkerke and Teixeira (2001) compared ECMWF* Reanalysis (ERA) results with observations from the First ISCCP $\dagger$ Regional Experiment (FIRE) (Albrecht et al. 1988). Their study showed that the ERA cloud cover and liquid-water path (LWP) are strongly underestimated, which causes the ERA downwelling short-wave radiation at the surface to be much larger than observed. Ma et al. (1996) demonstrate that in a coupled atmosphere-ocean model an underestimation of the stratocumulus cloud amount can lead to positive SST biases of about $5 \mathrm{~K}$. This is of a particular concern for simulations and predictions of El Niño Southern Oscillation (ENSO), since such errors can strongly affect the (sub)tropical circulations (Philander et al. 1996; Nigam 1997; Yu and Mechoso 1999). Furthermore, the presence of subtropical stratocumulus fields plays an important role in the entire tropical response to climate perturbations (Miller 1997). It is therefore vitally important that in GCMs stratocumulus cloud fields are accurately represented.

Stratocumulus clouds can exhibit a marked diurnal cycle (Wood et al. 2002). During the night, turbulence is driven by a strong long-wave radiative cooling near the top of the stratocumulus cloud. This usually results in vertically well-mixed STBLs. In contrast, the STBL can become decoupled during daytime due to absorption of solar radiation in the cloud layer. This implies that the cloud layer becomes stably stratified with respect to the sub-cloud layer, and the transport of heat and moisture from the surface into the cloud layer will be effectively reduced or will even be cut off. Because entrainment maintains a steady supply of relatively warm and dry air from above the inversion into the cloud layer, the cloud layer can rapidly thin or even disappear during daytime.

The EUROpean Cloud Systems (EUROCS) project used observations made in stratocumulus off the coast of California during FIRE I (Hignett 1991; Duynkerke and Hignett 1993) as a basis to set up a well-defined case for modelling the diurnal cycle of stratocumulus. The modelling results can be verified with observations of cloud cover, liquid-water path, cloud-base and cloud-top height, downwelling and short-wave radiation at the surface, and the turbulence structure of the boundary layer. The EUROCS stratocumulus diurnal cycle case adds to previous intercomparison studies that addressed other boundary-layer cloud regimes such as nocturnal stratocumulus (Moeng et al. 1996; Duynkerke et al. 1999), a stratocumulus to cumulus transition over the Atlantic Ocean observed during the Atlantic Stratocumulus Transition Experiment (ASTEX) (Bretherton et al. 1999), trade-wind cumuli capped by a strong inversion in the Atlantic Tradewind Experiment (ATEX) (Stevens et al. 2001), the diurnal cycle of shallow cumulus convection over land from the Atmospheric Radiation Measurement (ARM) project (Brown et al. 2002) and shallow cumulus over the ocean based on observations collected during the Barbados Oceanographic and Meteorological Experiment (BOMEX) (Siebesma et al. 2003). This study is a piece in the EUROCS chain that links detailed studies on a particular cloud regime like stratocumulus, cumulus (Lenderink et al. 2004) and deep convection (Guichard et al. 2004), to the representation of these cloud types in the Hadley circulation (Siebesma et al. 2004).

A detailed description of the EUROCS stratocumulus case is given in section 2. Section 3 discusses Large-Eddy Simulation (LES) results of the surface energy balance, the turbulence structure of the STBL, and the development of mesoscale fluctuations. The representation of stratocumulus in ten weather and climate GCMs and regional climate models is assessed from a comparison of the surface energy balance obtained with their respective single-column model (SCM) versions. Because the development

\footnotetext{
* European Centre for Medium-Range Weather Forecasts.

$\dagger$ International Satellite Cloud Climatology Project.
} 
of parametrizations for the entrainment rate in the STBL is currently one of the most challenging problems in boundary-layer meteorology, observations and LES results of entrainment rates for different stratocumulus cases are compared in section 4. Various suggestions for model improvements are summarized in section 5, and section 6 presents the main findings.

\section{OBSERVATIONS AND MODEL INITIALIZATION OF THE EUROCS STRATOCUMULUS} CASE

\section{(a) Surface-based observations}

The FIRE I stratocumulus experiment performed off the coast of southern California in July 1987 provides a very comprehensive set of data on marine stratocumulus from airborne, ground-based and satellite instruments (Albrecht et al. 1988). Several instruments were installed on San Nicolas Island $\left(33^{\circ} 15^{\prime} \mathrm{N}, 119^{\circ} 30^{\prime} \mathrm{W}\right)$ to monitor cloud properties with a high temporal resolution. Cloud-base height was measured by a Väisälä CT 12K laser ceilometer (Schubert et al. 1987). A sodar was used to estimate the inversion height (White 1999). The vertically integrated liquid-water content was retrieved using a three-channel $(20.6,21.65$ and $90.0 \mathrm{GHz})$ microwave radiometer as described by Hogg et al. (1983). The temporal evolution of the cloud conditions on San Nicolas Island during July 1987 is discussed in detail by Blaskovic et al. (1991), Betts (1990) and Albrecht et al. (1990). In addition, Hignett (1991) and Duynkerke and Hignett (1993) present the turbulence structure in the boundary layer as measured on 14 and 15 July 1987 by means of an instrumented tethered balloon.

\section{(b) Initial and boundary conditions}

During 1 to 19 July 1987, sixty-nine vertical profiles of temperature and relative humidity were measured by radiosondes. From these data, mean vertical profiles for the potential temperature and specific humidity were calculated by Duynkerke and Teixeira (2001), which are shown in Fig. 2. Because the inversion height is quite variable in time, the inversion structure is smoothed out in the averaged profile. To quantify the strength of the inversion, the jumps in liquid-water potential temperature and total water content were estimated from each individual sounding as well. This was done in a method similar to Kuo and Schubert (1988). For each of the soundings, we determined the cloud-top jump in total water $\Delta q_{\mathrm{t}}$ as follows. First the height of the inversion base was determined from the level above which the potential temperature strongly increased with height. Next, we computed the vertically averaged specific humidity in the layer $200 \mathrm{~m}$ above the inversion. Finally, we subtracted from this the average specific humidity in the layer which extends from 65 to $165 \mathrm{~m}$ above sea level (the island sounding site being $38 \mathrm{~m}$ above sea level). If the boundary layer is vertically well mixed, the specific humidity difference should be equivalent to the jump in total water at cloud top. The procedure for $\Delta \theta_{1}$ is followed identically for $\theta$. In this way, each sounding is characterized by a point in the $\left(\Delta \theta_{\mathrm{l}}, \Delta q_{\mathrm{t}}\right)$ plane as shown in Fig. 3. The average jump at cloud top is given by $\Delta \theta_{\mathrm{l}}=12 \mathrm{~K}$ and $\Delta q_{\mathrm{t}}=-3.0 \mathrm{~g} \mathrm{~kg}^{-1}$.

Figure 2 also shows the initial vertical profiles for liquid-water potential temperature, $\theta_{\mathrm{l}}$, and total water content, $q_{\mathrm{t}}$ :

$$
\begin{aligned}
& 0<z \leqslant 595 \mathrm{~m}\left\{\begin{array}{l}
\theta_{\mathrm{l}}=287.5 \\
q_{\mathrm{t}}=9.6
\end{array}\right. \\
& 595<z \leqslant 1200 \mathrm{~m}\left\{\begin{array}{l}
\theta_{\mathrm{l}}=299.5+0.0075(z-595) \\
q_{\mathrm{t}}=6.6-0.003(z-595)
\end{array}\right. \\
& \left.\begin{array}{l}
(\mathrm{K}) \\
\left(\mathrm{g} \mathrm{kg}^{-1}\right) \\
(\mathrm{K}) \\
\left(\mathrm{g} \mathrm{kg}^{-1}\right) .
\end{array}\right\}
\end{aligned}
$$



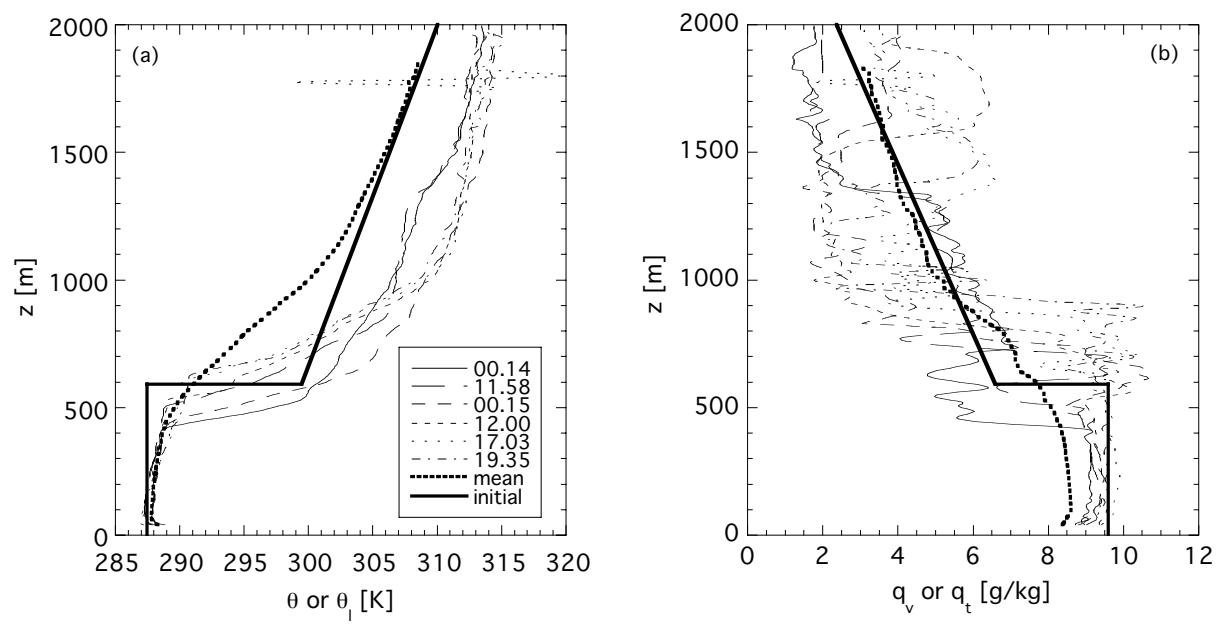

Figure 2. The observed vertical profiles of (a) potential temperature $\theta$ and (b) specific humidity $q_{\mathrm{v}}$ at 0014 and 1158 UTC on 14 July and $0015,1200,1703$ and 1935 UTC on 15 July. The mean of the observed profiles collected between 1 and 19 July 1987 is indicated by the thick dashed line. The thick solid lines are the initial conditions for the liquid-water potential temperature $\left(\theta_{\mathrm{l}}\right)$ and total water content $\left(q_{\mathrm{t}}\right)$ prescribed in the models.

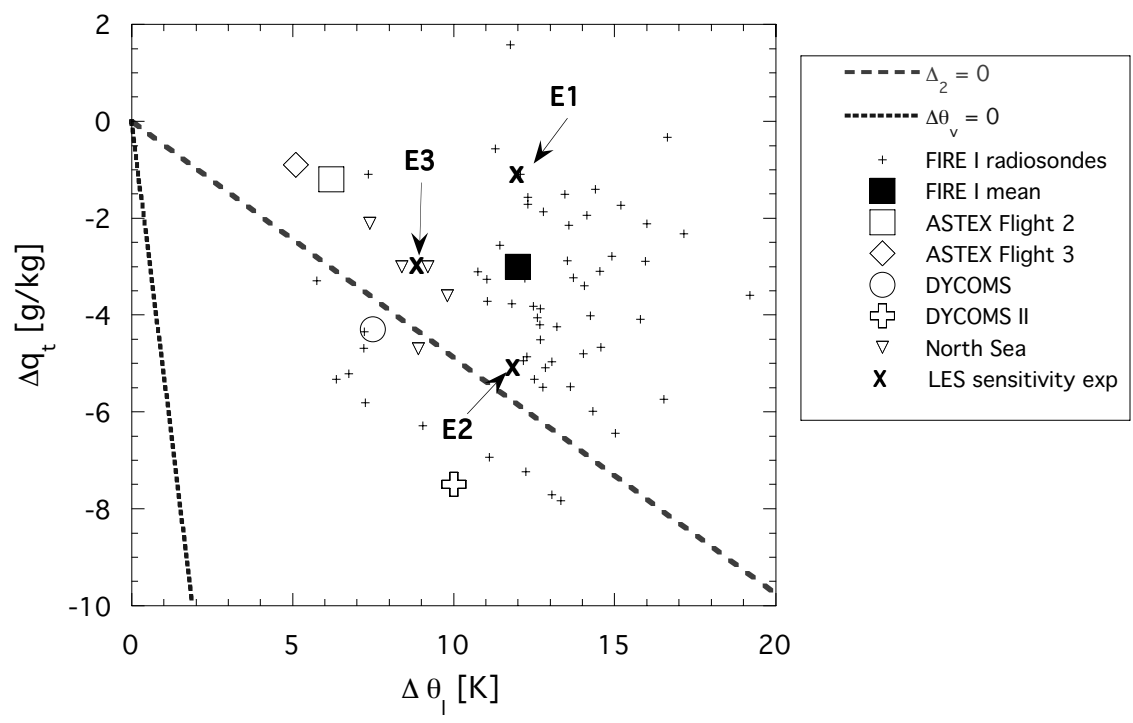

Figure 3. The $\left(\Delta \theta_{\mathrm{l}}, \Delta q_{\mathrm{t}}\right)$ plane, showing the thermodynamic instability curve for the clear convective boundary layer $\Delta \theta_{\mathrm{v}}=0$ and the cloud-top instability criterion proposed by Randall (1980) and Deardorff $(1980), \Delta_{2}=0$. The observed inversion jumps were obtained from high-vertical-resolution radiosonde soundings launched from San Nicolas Island during the period between 30 June and 19 July 1987, and the mean inversion jumps of stratocumulus cases observed during Flights 2 and 3 of the ASTEX First Lagrangian (De Roode and Duynkerke 1997), DYCOMS (Kawa and Pearson Jr 1989), Flight RF01 of DYCOMS II (Stevens et al. 2003) and five flights performed over the North Sea (Nicholls and Leighton 1986). The jumps of three LES sensitivity experiments are indicated by arrows. 
A comparison of the monthly mean values with observed vertical profiles during 14 and 15 July indicates that in the free atmosphere the total water contents are nearly the same, but the monthly mean potential temperature is about $5 \mathrm{~K}$ lower. The initial total water content in the boundary layer is set to a value that is close to the observations during 14 and 15 July, in order to give an initial cloud-base height of about $250 \mathrm{~m}$.

The large-scale (LS) surface pressure gradient for July 1987 (Fig. 2 of Duynkerke and Teixeira (2001)) gives a geostrophic wind direction (anticlockwise with respect to the $x$-direction) of about $\alpha_{\text {geo }}=305^{\circ}$. Due to surface friction, the observed boundarylayer wind direction $\alpha$ deviates from the geostrophic value. This value for $\alpha$ was also observed on 14 and 15 July 1987 at San Nicolas Island by Hignett (1991). The geostrophic wind speed is prescribed as $U_{\text {geo }}=6.0 \mathrm{~m} \mathrm{~s}^{-1}$, and the resulting geostrophic forcing in the $(x, y)$ direction is: $\left(u_{\mathrm{geo}}, v_{\mathrm{geo}}\right)=U_{\mathrm{g}}\left(\cos \alpha_{\mathrm{geo}}, \sin \alpha_{\mathrm{geo}}\right)$. In the models the initial wind fields were set to the geostrophic winds

$$
(u, v)=U_{\text {geo }}\left(\cos \alpha_{\text {geo }}, \sin \alpha_{\text {geo }}\right) .
$$

The surface temperature and pressure are prescribed as $T_{\mathrm{s}}=289.0 \mathrm{~K}$ and $p_{\mathrm{s}}=$ $1012.5 \mathrm{hPa}$, respectively (Duynkerke and Teixeira 2001). Because the wind is blowing almost parallel to the isotherms of the sea surface temperature, this means that the surface temperature hardly changes as the air flows south-eastwards (Duynkerke and Hignett 1993). The specific humidity at the sea surface is set to its saturated value at the sea surface temperature, $q_{\mathrm{s}}=11.1 \mathrm{~g} \mathrm{~kg}^{-1}$. The surface roughness length is set to $2 \times 10^{-4} \mathrm{~m}$, and the Coriolis parameter $f_{\mathrm{c}}=8.0 \times 10^{-5} \mathrm{~s}^{-1}\left(33.3^{\circ} \mathrm{N}, 119.5^{\circ} \mathrm{W}\right)$.

\section{(c) Forcings}

The LS subsidence rate $\bar{w}$ is prescribed as

$$
0<z \leqslant 1200 \mathrm{~m} \quad \bar{w}=-1 \times 10^{-5} z \quad\left(\mathrm{~m} \mathrm{~s}^{-1}\right) .
$$

It is hard to obtain the LS subsidence rate directly from observations. The subsidence rate in (3) is based on test simulations with the IMAU LES model, and approximately balances the diurnally averaged entrainment rate. Subsidence rates from (3) are nearly a factor of two larger than the average values over San Nicholas Island presented by Neiburger (1960).

To balance the subsidence heating and drying above the boundary layer, a LS advection term is included in the simulation:

$$
0<z \leqslant 1200 \mathrm{~m} \begin{cases}\left(\mathrm{~d} \theta_{\mathrm{l}} / \mathrm{d} t\right)_{\mathrm{LS}}=-7.5 \times 10^{-8} \max (z, 500) & \left(\mathrm{K} \mathrm{s}^{-1}\right) \\ \left(\mathrm{d} q_{\mathrm{t}} / \mathrm{d} t\right)_{\mathrm{LS}}=3.0 \times 10^{-11} \max (z, 500) & \left(\mathrm{kg} \mathrm{kg}^{-1} \mathrm{~s}^{-1}\right) .\end{cases}
$$

In the boundary layer, the LS horizontal advection tendencies approximately counteract the divergence of the turbulent fluxes of heat and moisture. The $u, v, \theta_{\mathrm{l}}$ and $q_{\mathrm{t}}$ profiles in the damping layer are relaxed towards the geostrophic wind and initial thermodynamic profiles (1) and (2), respectively.

The net upward long-wave radiation is parametrized as

$$
F_{\mathrm{L}}(z)=\Delta F_{\mathrm{L}, \text { tot }} \exp \left\{-a L W P\left(z, z_{\text {top }}\right)\right\},
$$

where $\Delta F_{\mathrm{L} \text {,tot }}=70 \mathrm{~W} \mathrm{~m}^{-2}$ (Duda et al. 1991) is the long-wave radiative flux divergence at the cloud top, $a=130 \mathrm{~m}^{2} \mathrm{~kg}^{-1}$ is a constant, and $z_{\text {top }}=1200 \mathrm{~m}$ is the top of the 
TABle 1. Participating Large-Eddy Simulation and Single-Column Models

\begin{tabular}{llclr}
\hline Participating scientists & Institution* & LES & \multicolumn{1}{c}{ SCM } & $N_{\text {BL,SCM }}$ \\
\hline M. C. van Zanten & IMAU & Y & & \\
A. Chlond, I. Sednev, F. Müller & MPI & Y & ECHAM & 9 \\
A. P. Lock & UKMO & Y & UKMO & 6 \\
E. Sánchez, D. Olmeda, J. Calvo & INM & & HIRLAM & 8 \\
E. Sánchez, J. Cuxart & INM & Y & MESO-NH & 60 \\
C.-H. Moeng & NCAR & Y & & \\
D. Lewellen & WVU & Y & & \\
G. Lenderink & KNMI & & RACMO & 59 \\
C.-L. Lappen & CSU & & Mass-flux & 60 \\
S. Cheinet & LMD & LMD GCM & 12 \\
H. Grenier & MetFr I & ARPEGE Climate & 3 \\
J. M. Piriou & MetFr II & ARPEGE NWP & 6 \\
M. Köhler & ECMWF & ECMWF & 8 \\
\hline
\end{tabular}

* See author affiliations for institution names in full.

$N_{\mathrm{BL}, \mathrm{SCM}}$ is the number of vertical grid points in the boundary layer $(0<z \leqslant 595 \mathrm{~m})$ after initialization at $00 \mathrm{~h}$ local time.

model domain. The liquid-water path between $z_{1}$ and $z_{2}$ is given by

$$
\operatorname{LWP}\left(z_{1}, z_{2}\right)=\int_{z_{1}}^{z_{2}} \rho_{0} q_{1} \mathrm{~d} z
$$

where $\rho_{0}=1.14 \mathrm{~kg} \mathrm{~m}^{-3}$ is the mean density and $q_{1}$ is the liquid-water content.

The solar radiation is a function of the solar zenith angle $\theta_{0}\left(\mu_{0}=\cos \theta_{0}\right)$ and the optical depth $\tau$ which is parametrized as:

$$
\tau(z)=\frac{3}{2} \frac{L W P\left(z, z_{\mathrm{top}}\right)}{r_{\mathrm{eff}} \rho_{\mathrm{l}}},
$$

where $r_{\text {eff }}=10 \mu \mathrm{m}$ is the effective radius and $\rho_{\mathrm{l}}=1000 \mathrm{~kg} \mathrm{~m}^{-3}$ is the density of water. The net downward short-wave radiation $F_{\mathrm{S}}$ is obtained from the analytical solution of the delta-Eddington approximation, which is summarized in the appendix. The removal of liquid water by precipitation is not taken into account.

\section{(d) Models}

In total six LES models and ten SCMs have participated in this study (see Table 1). Details about the numerical codes of these LES models can be found in Duynkerke et al. (1999), Stevens et al. (2001), Brown et al. (2002), and Siebesma et al. (2003). Periodic lateral boundary conditions were applied to the LES models. A spatially uncorrelated random perturbation between -0.1 and $0.1 \mathrm{~K}$ was applied to the initial temperature field at all grid points. Throughout the domain, an initial value for sub-grid turbulent kinetic energy of $1 \mathrm{~m}^{2} \mathrm{~s}^{-2}$ was specified. The grid size in the horizontal is $50 \mathrm{~m}$ and in the vertical $10 \mathrm{~m}$, covering a domain of $2.5 \mathrm{~km}$ in $x$ and $y$ and $1.2 \mathrm{~km}$ in $z$.

Ten SCM versions of (semi-)operational numerical weather-prediction and climate models were used. In an SCM, the LS tendencies are prescribed, while the non-advective tendencies of prognostic variables are predicted by the model's physical parametrizations. Details of the ARPEGE, ECMWF, ECHAM, RACMO, UKMO, MESO-NH and HIRLAM boundary-layer mixing schemes are summarized by Lenderink et al. (2004), who report on the EUROCS SCM intercomparison of the diurnal cycle of shallow cumulus over land. The CSU SCM model is a unified mass-flux model that has been developed recently by Lappen and Randall (2001). It includes a prognostic equation for 
TABLE 2. LARGE-EDDY SIMULATION RESULTS OF THE MEAN SURFACE ENERGY BALANCE FROM 12 TO $36 \mathrm{~h}$ LOCAL TIME

\begin{tabular}{|c|c|c|c|c|c|c|}
\hline Model & $H$ & $L E$ & $F_{\mathrm{S}}$ & $F_{\mathrm{L}}$ & $\bar{G}$ & LWP \\
\hline IMAU & 4.0 & 27.3 & -196 & 0.1 & 165 & 93 \\
\hline MPI & 4.1 & 23.0 & -171 & 0.0 & 144 & 116 \\
\hline UKMO & 7.5 & 20.4 & -124 & 0.0 & 96 & 168 \\
\hline INM & 5.1 & 22.6 & -164 & 0.0 & 136 & 130 \\
\hline NCAR & 13.9 & 24.3 & -190 & 0.0 & 152 & 110 \\
\hline WVU & 8.6 & 28.1 & -185 & 0.0 & 148 & 95 \\
\hline LES mean & $7.2 \pm 3.8$ & $24.3 \pm 2.9$ & $-172 \pm 26$ & $0.02 \pm 0.04$ & $140 \pm 24$ & $119 \pm 28$ \\
\hline Observations & & & -114 & & & 130 \\
\hline Monthly mean observations & & & -185 & & & 73 \\
\hline
\end{tabular}

$H$ is the sensible heat flux, $L E$ the latent heat flux, $F_{\mathrm{S}}$ the net short-wave radiative flux, $F_{\mathrm{L}}$ the net long-wave radiative flux, $G$ the energy flow into the sea surface (all W m $\mathrm{m}^{-2}$ ) and LWP the mean liquid-water path $\left(\mathrm{g} \mathrm{m}^{-2}\right)$. The observed mean values are computed from measurements collected on 14 and 15 July 1987 from 00 to $48 \mathrm{~h}$ local time, and the monthly mean values represent averages from data collected between 1 and 19 July 1987. The net short-wave radiation was computed from the observed downwelling component assuming a ground albedo $A_{\text {sfc }}=0.05$.

the vertical mass flux, and vertical fluxes are proportional to the vertical mass flux and the difference between the updraught and downdraught value of the quantity. The mixing scheme of the single-column version of the LMD GCM utilizes a K-profile approach (Cheinet 2002). Note that because most of the SCMs are the operational versions of their parent GCMs, the radiation codes suggested in this paper were not implemented in all SCMs, and the models may generate precipitation or shallow cumulus convection by their microphysics and convection schemes, respectively. Additional sensitivity experiments have been carried out to assess the role of the vertical resolution and the convection scheme.

Because in the EUROCS stratocumulus case the radiation and LS forcings are prescribed, variations in the tendencies of heat and moisture must be primarily attributed to the SCM's turbulent transport and cloud schemes. As such, possible deficiencies in the boundary-layer parametrization package are straightforward to identify.

Since the initial state is reasonably close to the radiosonde soundings during 14 and $15 \mathrm{July}$, we will compare the model results with observations from this period. The model simulations start at 0800 UTC ( $=00 \mathrm{~h}$ Local Time (LT)) 14 July and last at least 37 hours. Since the monthly-mean atmospheric state does not differ very much from the initial profiles either, we will also present monthly-mean values of the observations.

\section{Simulation RESUlts}

(a) Surface energy balance

(i) Large-eddy simulation results. The surface energy balance reads

$$
-G=H+L E+F_{\mathrm{S}}+F_{\mathrm{L}},
$$

where $H$ and $L E$ represent the surface sensible and latent heat fluxes, respectively, and $F_{\mathrm{S}}$ and $F_{\mathrm{L}}$ the net short-wave and long-wave radiative fluxes, respectively. The net energy flow into the ocean, $-G$, is computed as a residual. According to Table 2, the computed turbulent fluxes of heat and moisture at the surface are fairly consistent among the LES models, and the net short-wave radiative flux is the dominant component of the surface energy balance. Because the cloud droplet effective radius used in the LESs has a constant value, the transmissivity of the cloud layer depends only on the LWP, as 


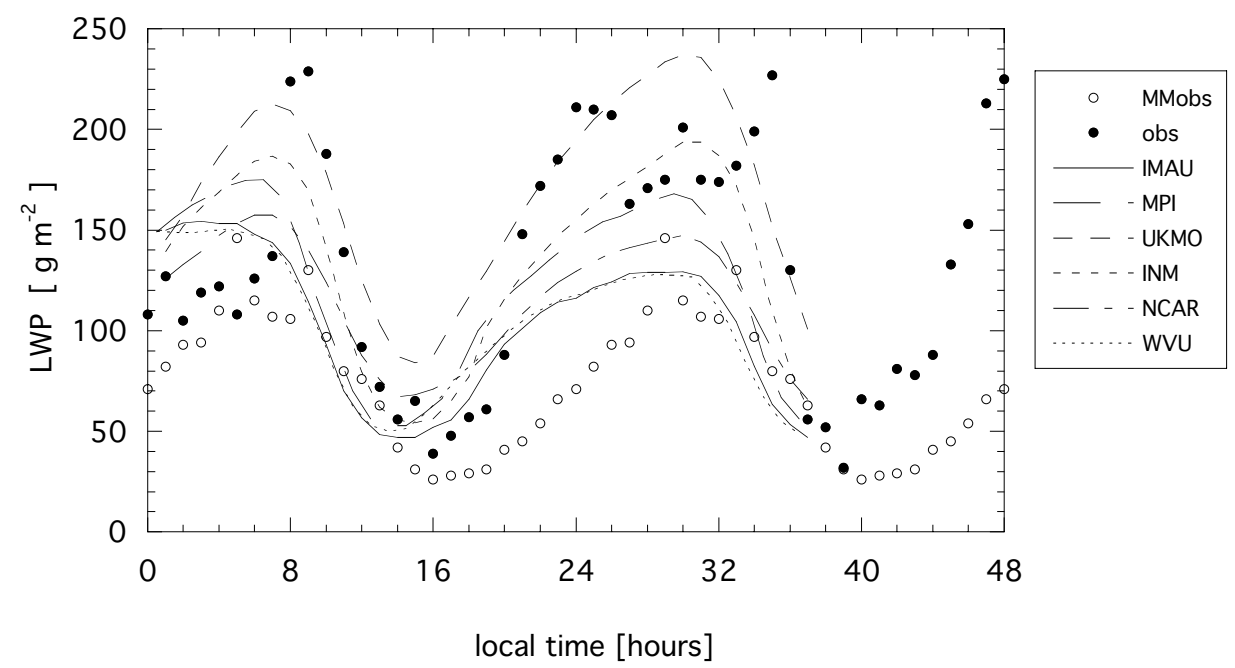

Figure 4. Modelled liquid-water path (lines) from six large-eddy simulation models as a function of time for 14 and 15 July 1987 (from 0 to 48 hours local time). The solid dots are the hourly mean observed values (obs) and the open circles are the hourly monthly-mean values (MMobs).

can be seen from (7). Therefore, the differences in the net short-wave radiative fluxes are entirely due to the variations in the computed LWPs. Inspection of the mean LWP values shows that larger numbers for the LWP correspond to smaller numbers of the net short-wave radiative flux, and vice versa. The values for the diurnal mean LWP from the LES models range from a minimum of 93 (IMAU) to a maximum of $168 \mathrm{~g} \mathrm{~m}^{-2}$ (UKMO).

In Fig. 4 the LWPs from the LES models are compared with the retrievals of the microwave radiometer from 14 and 15 July 1987, and the hourly monthly-mean diurnal variation. All the LESs capture the strong diurnal variation in LWP due to the forcing imposed by the short-wave heating on the cloud layer. Like the observations, the maximum cloud thickness is found during the night, and the cloud deck gradually thins until noon. However, the thinning is not sufficient to break up the cloud; in all the LESs the cloud cover remains equal to unity. After 30 hours of simulation time, the minimum value (IMAU) of modelled LWP is about half the maximum value (UKMO). This variation is about as large as the difference between the monthly mean and observed diurnal cycle. Note that the LWP is very sensitive to small changes in the thermodynamic structure of the boundary layer. If the boundary layer is vertically well-mixed then the liquid-water content $q_{1}$ increases approximately linearly with height. In that case, from (6) it follows that (Albrecht et al. 1990)

$$
L W P \propto\left(z_{\mathrm{ct}}-z_{\mathrm{cb}}\right)^{2},
$$

where $z_{\mathrm{ct}}$ and $z_{\mathrm{cb}}$ represent the cloud-top and cloud-base heights. As an example, for the EUROCS stratocumulus case this implies that for a cloud layer that is $350 \mathrm{~m}$ thick, a change of just $20 \mathrm{~m}$ leads to a subsequent variation in the LWP of nearly $12 \%$.

Figure 5 compares the modelled cloud-base and cloud-top height evolution to the observations. The top of a stratocumulus cloud layer is usually located just below the inversion height $z_{\mathrm{i}}$, the latter varying with time according to

$$
\frac{\mathrm{d} z_{\mathrm{i}}}{\mathrm{d} t}=\bar{w}\left(z_{\mathrm{i}}\right)+w_{\mathrm{e}},
$$




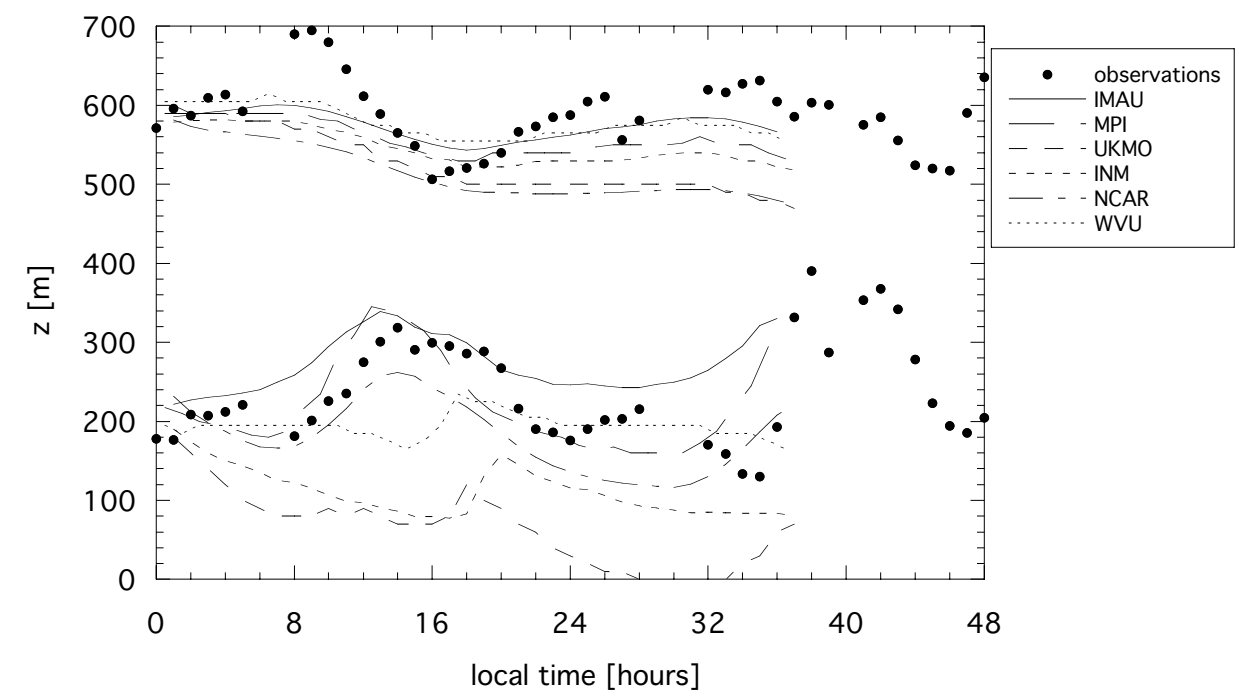

Figure 5. The cloud-base and cloud-top height from observations and six large-eddy simulation models as a function of time for 14 and 15 July 1987 ( 0 to 48 hours local time).

TABLE 3. SCM RESULTS OF THE MEAN SURFACE ENERGY BALANCE FROM 12 TO $36 \mathrm{~h}$ LT

\begin{tabular}{lrlrrrr}
\hline Model & $H$ & $L E$ & $F_{\mathrm{S}}$ & $F_{\mathrm{L}}$ & $G$ & \multicolumn{1}{c}{ LWP } \\
\hline KNMI RACMO & 4.0 & 26.2 & -272 & 10.3 & 232 & 33 \\
INM MESO-NH & 6.2 & 21.0 & -130 & 0.0 & 103 & 159 \\
INM HIRLAM & 6.7 & 17.4 & -191 & 0.0 & 167 & 98 \\
CSU Mass-flux & 14.8 & 24.5 & -119 & 0.0 & 80 & 161 \\
LMD GCM & 0.2 & 15.9 & -237 & 20.8 & 200 & 41 \\
MPI ECHAM & 5.5 & 29.6 & -119 & 8.2 & 76 & 156 \\
MetFr ARPEGE Climate & 24.0 & 24.0 & -262 & 0.3 & 214 & 57 \\
UKMO & 10.3 & 26.0 & -173 & 15.7 & 121 & 75 \\
MetFr ARPEGE NWP & 4.3 & 17.9 & -306 & 78.4 & 205 & 14 \\
ECMWF & 5.3 & 21.4 & -249 & 21.8 & 200 & 87 \\
SCM mean & $8.1 \pm 6.8$ & $22.4 \pm 4.4$ & $-206 \pm 69$ & $15.6 \pm 23.7$ & $160 \pm 59$ & $88 \pm 55$ \\
\hline
\end{tabular}

Variables and units are as Table 2.

where $w_{\mathrm{e}}$ is the entrainment rate. An inspection of the cloud-top height evolution therefore gives a good appreciation of differences in the entrainment rate. After 37 hours simulation time, the typical scatter in the cloud-top heights is about $100 \mathrm{~m}$. Such a variation corresponds roughly with a typical difference in the mean entrainment rate of the order of $1 \mathrm{~mm} \mathrm{~s}^{-1}$. The differences in the cloud-layer depth are mainly due to variations in the simulated cloud-base height. The lowest cloud bases are due to larger moistening rates of the boundary layer, and are found for models that simulate the smallest entrainment rates. There is a much larger amplitude in the observed cloud-top height during the first diurnal cycle than in the simulations. Possibly, a diurnal cycle in the subsidence rate may play a role, as was found from an observational study of stratocumulus over the south-east Pacific region (Bretherton et al. 2004).

(ii) Single-column model results. Table 3 displays the mean surface energy balance components as computed by the SCMs. The turbulent fluxes at the surface compare well with the LES model results. The scatter in the LWPs, shown in Fig. 6, is reflected in the amount of downwelling short-wave radiation absorbed at the sea surface, which 


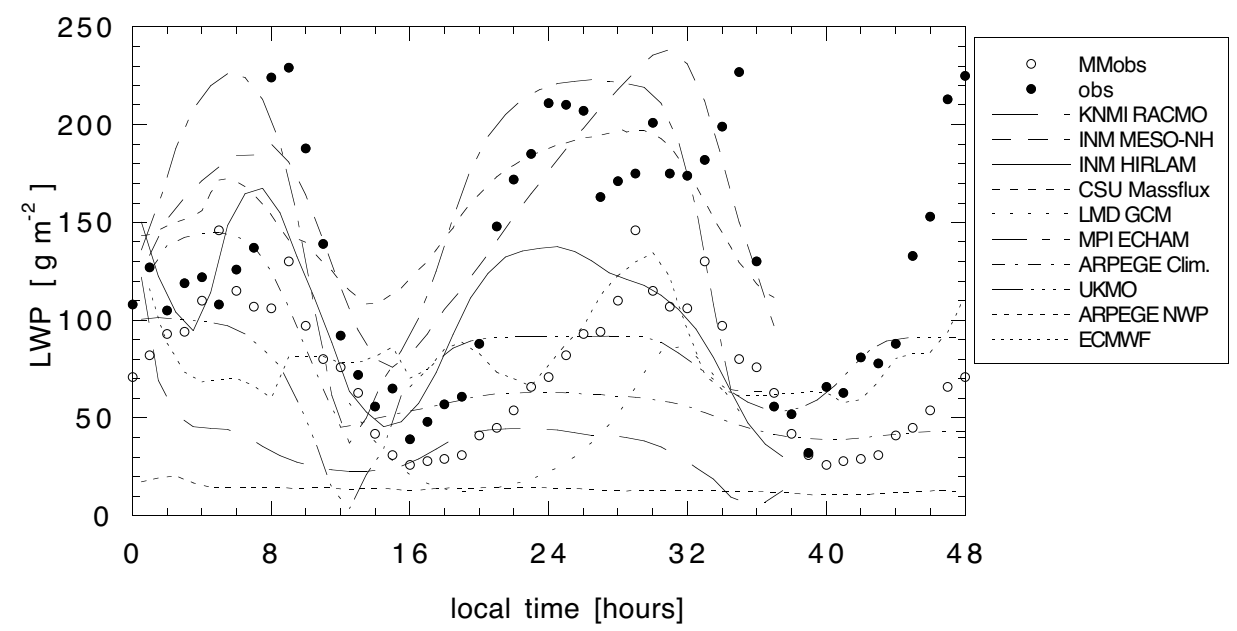

Figure 6. As Fig. 4, but for ten single-column models.

varies considerably among the SCMs. About half of the SCMs compute lower values for the LWP than is observed. These models give a much larger amount of downwelling short-wave radiation absorbed at the sea surface. This error may be partly counteracted by a significant decrease in the downwelling long-wave radiation at the sea surface due to a decrease of the cloud emissivity.

Figure 7 shows that the majority of the SCMs tend to compute a cloud-top height that is too low in comparison with the observations and LES results. According to (10), this suggests that for these SCMs the entrainment rate is probably too low. In contrast to the observations, some SCMs compute a cloud cover less than unity, in particular during daytime (see Fig. 8). Because the latent and sensible heat fluxes at the surface in the SCMs and the LESs are in a fairly good agreement, any different entrainment rate of heat and moisture will probably explain a good deal of the discrepancy in the simulated cloud evolution. A better representation of stratocumulus clouds in GCMs can likely be achieved by improving the parametrization of entrainment. In the next section this topic will be discussed in detail.

Clearly, there is wide disagreement in the SCM results. Some models predict a cloud layer that gradually dissipates, whereas other models maintain a solid cloud layer. The analysis of the model results is complicated by the different physical packages that have been used. Therefore, a few additional sensitivity experiments were carried out to explore the role of the microphysics scheme, the convection scheme, and the effect of the vertical resolution. In the Conv_Off (Conv_On) simulations, the convection routine was turned off (on). In the Conv_Off run, the turbulence mixing scheme takes care of all turbulent transports in the cloud layer. In the ECHAM and RACMO models, the turbulence scheme is based on moist physics, which enables the simulation of realistic transports of heat and moisture in the cloud layer. These simulations exclude precipitation, and the long-wave and short-wave radiation routines were coded according to the case set-up. This approach facilitates a direct comparison with the LES results, and these two simulations are intended to verify the performance of the PBL models at representing stratocumulus convection excluding all model components except vertical advection. As the PBL gets decoupled during the day, it is also relevant to evaluate cumulus convection schemes in this context. These SCM simulations were done on a 


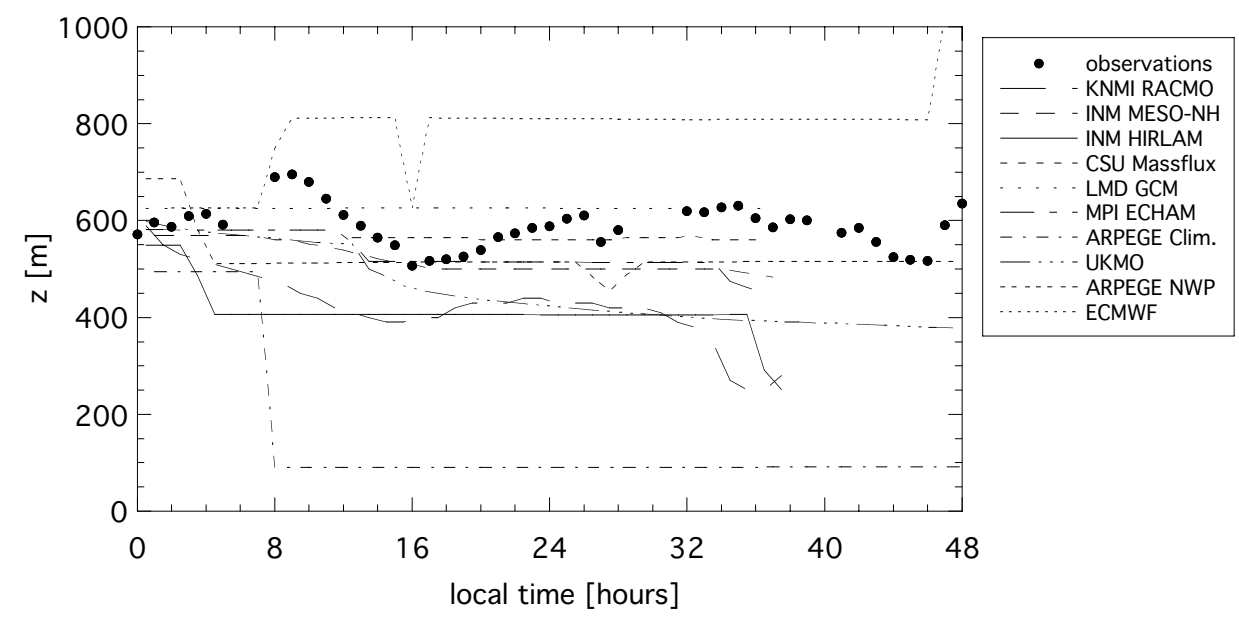

Figure 7. The cloud-top height from observations (solid dots) and ten single-column model simulations (lines) as a function of time for 14 and 15 July 1987 ( 0 to 48 hours local time).

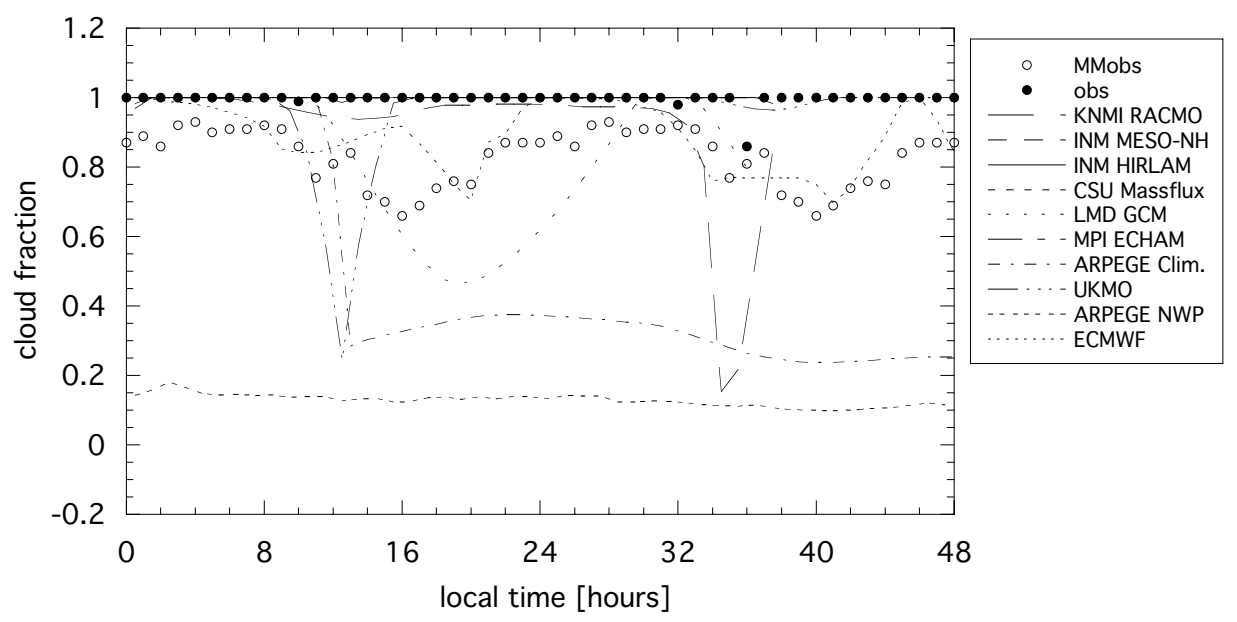

Figure 8. The observed (solid dots) and monthly mean (open circles) cloud cover, and results from ten singlecolumn model simulations (lines) as a function of time for 14 and 15 July 1987 ( 0 to 48 hours local time).

vertical resolution as is currently implemented in the ECMWF model (60 levels vertical resolution, with 8 grid levels in the boundary layer at the initialization time). To assess the role of the vertical grid resolution and to minimize the effect of numerical errors, two additional experiments were done on a finer vertical resolution (12 grid levels in the boundary layer), labelled as Conv_Off_HR and Conv_On_HR, respectively.

Table 4 displays the diurnal mean LWP from four SCMs. It appears that for the RACMO model simulations with the convection scheme turned on, cumulus convection is triggered leading to a very rapid entrainment of dry air into the boundary layer and a subsequent rapid decline of the cloud liquid-water path. Surprisingly, in ECMWF the liquid-water path increases when the convection scheme is turned on. This is caused by the detrainment of cloud liquid water by the convection scheme which is an important source of cloud liquid water in the ECMWF cloud scheme (see also Lenderink et al. (2004)). Also, the experiments illustrate the sensitivity of the model results to the 
TABLE 4. THE MEAN LIQUID-WATER PATH $\left(\mathrm{g} \mathrm{m}^{-2}\right)$ FROM 12 TO $36 \mathrm{~h} \mathrm{LOCAL}$ TIME FOR FOUR SENSITIVITY EXPERIMENTS

\begin{tabular}{lcccc}
\hline Model & Conv_Off & Conv_On & Conv_Off_HR & Conv_On_HR \\
\hline KNMI RACMO & 213.8 & 2.2 & 81.8 & 0.6 \\
MPI ECHAM & 256.1 & 62.9 & 107.2 & 113.1 \\
ECMWF & 65.7 & 95.6 & - & - \\
INM HIRLAM & 410.9 & 401.8 & - & - \\
\hline
\end{tabular}

Conv_Off (Conv_On) is performed with the convection scheme switched off (on), and 'HR' denotes a run with a finer vertical resolution. In all the simulations the precipitation scheme was turned off.

vertical resolution used. In the RACMO and ECHAM models, for simulations with the convection scheme turned off, an increase in the vertical resolution leads to a decrease in the mean LWP by about a factor of two. Lastly, the HIRLAM model sensitivity experiments suggest that, in the operational version of the model, the precipitation scheme is very actively removing liquid water from the cloud (see Table 3), as the mean LWP increases by more than a factor of 4 if the precipitation scheme is switched off.

\section{(b) Turbulence structure}

The turbulence observations collected by means of a tethered balloon during FIRE I, discussed in detail by Hignett (1991), facilitate a comparison with the results obtained from the LES models. In particular, we will consider the vertical velocity variance, $\overline{w^{\prime} w^{\prime}}$, and the buoyancy flux, $B=\left(g / \theta_{0}\right) \overline{w^{\prime} \theta_{\mathrm{v}}^{\prime}}$, with $g$ the acceleration due to gravity, and $\theta_{0} \approx 300 \mathrm{~K}$ a reference temperature. The observations and the LES results are presented for both night-time and daytime in Fig. 9. The LES results are in a good qualitative agreement with the observations and fall within the range of scatter in the observations, although the vertical velocity variance during night-time seems to be slightly overpredicted by most of the LES models. It can be concluded that the LES models are all capable of reproducing fairly well the observed turbulence structure during the diurnal cycle.

Clearly, there are distinct differences in the turbulence structure during daytime and night-time. During the night, long-wave radiative cooling near cloud top is the dominant process that drives the turbulent mixing throughout the boundary layer. In addition, latent heat release effects support a positive buoyancy flux in the cloud layer. The maximum vertical velocity variance is located in the upper half of the boundary layer. During the day the effect of short-wave radiative absorption in the cloud layer becomes manifest. The short-wave radiative warming of the cloud layer leads to a significant reduction of the buoyancy flux. The slightly negative buoyancy fluxes in the middle of the boundary layer tend to damp the vertical turbulent motions leading to a minimum vertical velocity variance near the middle of the boundary layer. This vertical velocity variance profile characterizes a decoupled boundary layer and indicates that the moist turbulent eddies driven from the surface cannot now reach the cloud layer. Because entrainment maintains a steady supply of relatively warm and dry air from above the inversion into the cloud layer, the cloud layer tends to thin during daytime, as clearly illustrated from the LWP evolution shown in Fig. 4. Because decoupling leads to different heating and moistening rates in the sub-cloud and cloud layers, conserved quantities like $\theta_{\mathrm{l}}$ and $q_{\mathrm{t}}$ cannot now be maintained in a vertically well-mixed state.

The interaction between entrainment rate, buoyancy fluxes and vertical velocity variance is nicely illustrated from the LES results during the night-time period. The IMAU model generates the largest entrainment rate, though it has the lowest vertical 

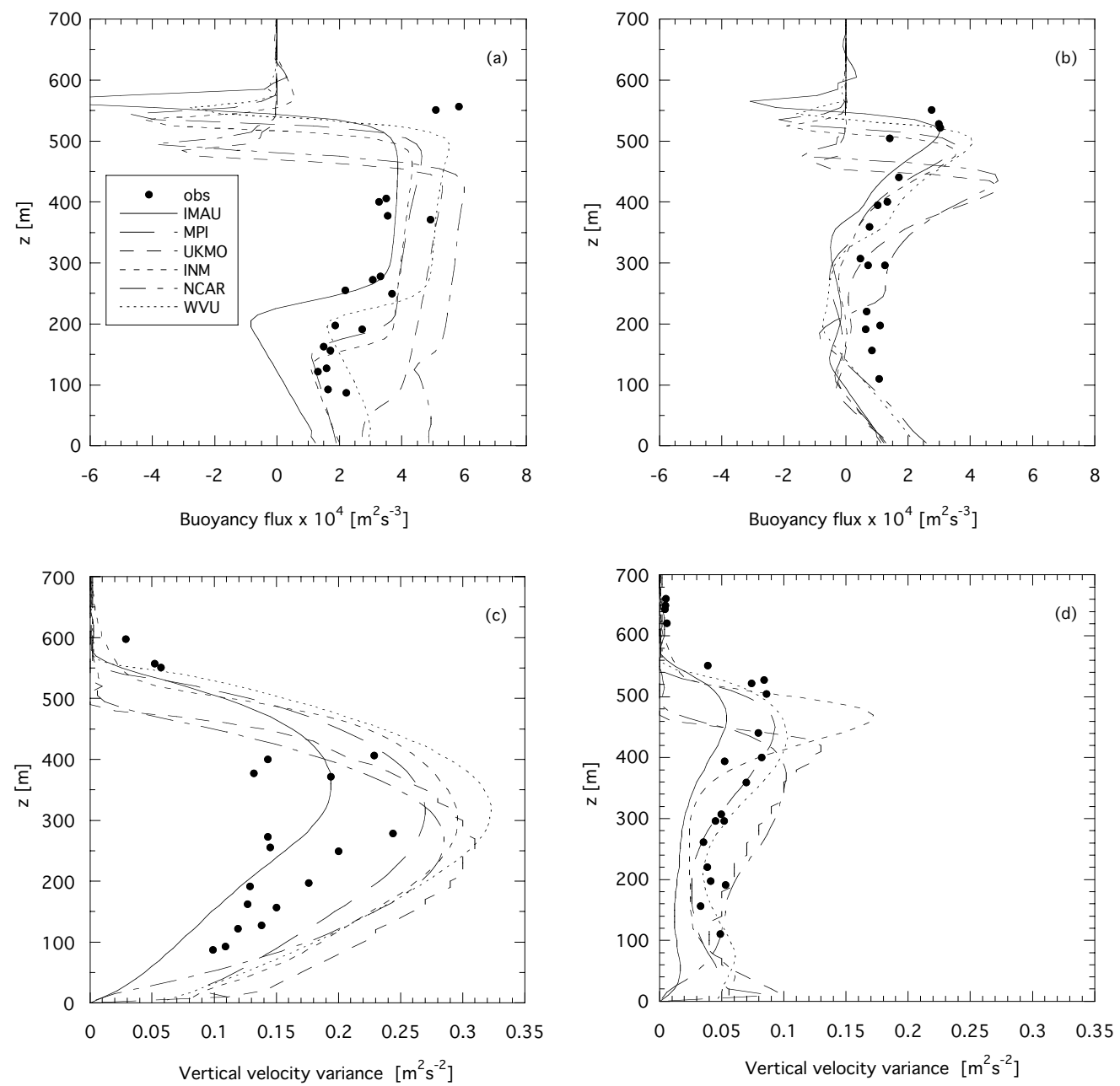

Figure 9. Vertical profiles of observations (solid dots) and six large-eddy simulation (LES) results (lines): buoyancy flux during (a) night-time, and (b) daytime, and the vertical velocity variance during (c) night-time and (d) daytime. LES results represent hourly averaged values between 23 and $24 \mathrm{~h}$ (night) and 35 and $36 \mathrm{~h}$ local time (day).

velocity variances. This indicates that there is no linear relation between the vertical velocity variance and the entrainment rate. Below the shallow layer that is radiatively cooled, the buoyancy flux is determined by the entrainment flux and a fixed radiative flux divergence, whereas a larger entrainment rate results in a more negative entrainment buoyancy flux. This leads to reduced buoyancy fluxes in the cloud layer and, consequently, smaller vertical velocity variances.

\section{(c) Stratocumulus mesoscale fluctuations}

The satellite image shown in Fig. 1 reveals that the stratocumulus cloud field is dominated by mesoscale structures, a phenomenon that was also frequently observed from aircraft during FIRE I (Moyer and Young 1994). Cahalan and Snider (1989) analysed observations of the microwave radiometer installed on San Nicholas Island during FIRE I and found that the vertically integrated liquid-water content exhibits a 


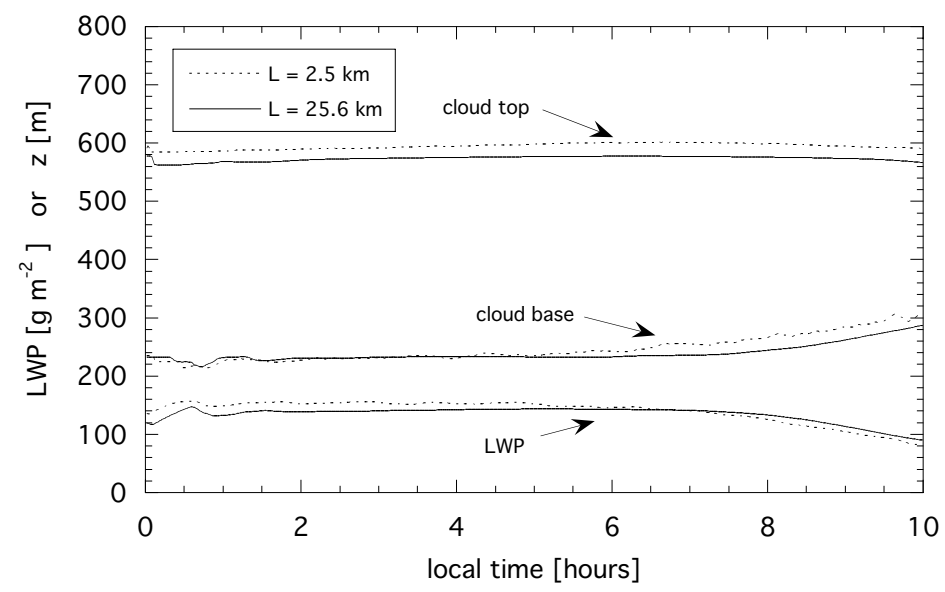

Figure 10. The cloud-base and cloud-top heights, and the liquid-water path as a function of local time. The two line styles represent results from large-eddy simulations on the small $\left(2.5 \times 2.5 \mathrm{~km}^{2}\right)$ and large $\left(25.6 \times 25.6 \mathrm{~km}{ }^{2}\right)$ horizontal domains.

$-5 / 3$ power law up to horizontal length-scales well above $100 \mathrm{~km}$. Such mesoscale variations give rise to errors in radiative transfer computations that assume a horizontally homogeneous cloud layer. A horizontally varying liquid-water field will decrease the mean albedo compared to a horizontally uniform field, since the albedo of optically thick regions saturates as the optical depth is increased (Cahalan et al. 1994).

Brown (1999) presented results from a series of LESs of shallow cumulus convection with different grid resolutions. It appeared that many of the ensemble-averaged turbulence statistics are insensitive to increases in resolution, but the cloud fields change markedly. Because mesoscale fluctuations frequently dominate stratocumulus cloud structures, an additional LES was performed with an increased horizontal domain size of $25.6 \times 25.6 \mathrm{~km}^{2}$, and a resolution of $(100,100,15) \mathrm{m}$ in the $(x, y, z)$ directions, to allow for the development of mesoscale structures.

Figure 10 shows that the time evolution of the cloud-base and cloud-top heights and the LWP are hardly sensitive to the horizontal domain sizes. There is a small difference in the cloud-top height at the initialization due to the difference in the vertical grid resolution (10 and $15 \mathrm{~m}$ for the simulation on the small and large horizontal domains, respectively). The fact that the cloud-top and cloud-base heights have the same tendencies indicates that the evolution of the mean state of the boundary layer is consistent in the two simulations.

Figure 11 shows the LWP fields at two different domain sizes after 8 hours of simulation time. Despite the fact that the mean LWPs do not differ very much, the cloud structures appear remarkably different and it appears that the small horizontal domain size acts to limit the growth of mesoscale cloud cells.

For the purpose of radiative transfer computations, the probability density function for the liquid-water path fluctuations, $P\left(L W P^{\prime}\right)$, is the relevant quantity to consider (Cahalan et al. 1994). Figure 12 shows $P\left(L W P^{\prime}\right)$ for the small and large domain simulations, in addition to $P\left(q_{\mathrm{t}}^{\prime}\right)$, which is relevant for microphysical computations (Wood and Field 2000). Clearly, the PDFs depend on the horizontal domain size. The simulation on the small domain has relatively more columns that have an LWP close to the mean value, whereas the large domain allows for a broader LWP distribution. A similar distribution is found for the total water content in the middle of the cloud 


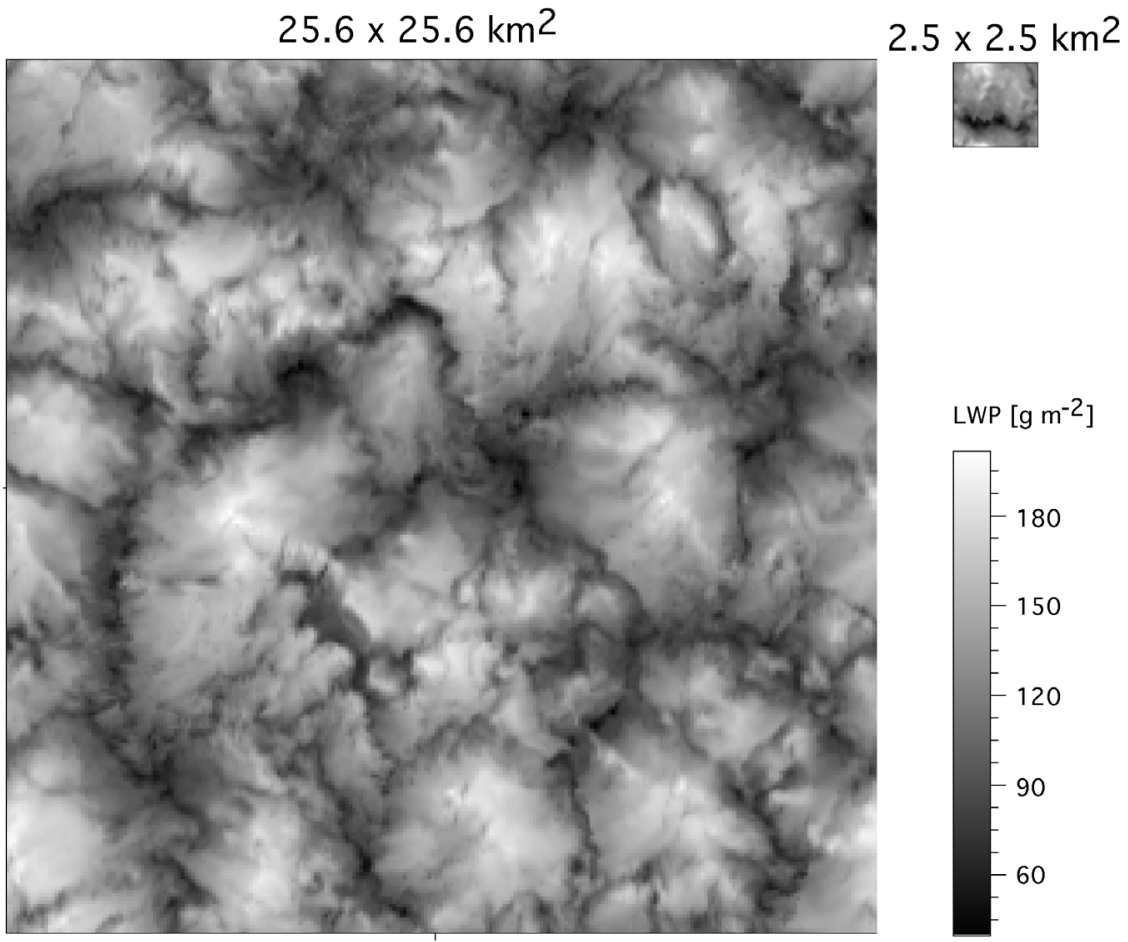

Figure 11. The liquid-water path field at $08 \mathrm{~h}$ local time from the IMAU large-eddy simulation on the small $\left(2.5 \times 2.5 \mathrm{~km}^{2}\right)$ and large $\left(25.6 \times 25.6 \mathrm{~km}^{2}\right)$ horizontal domains.
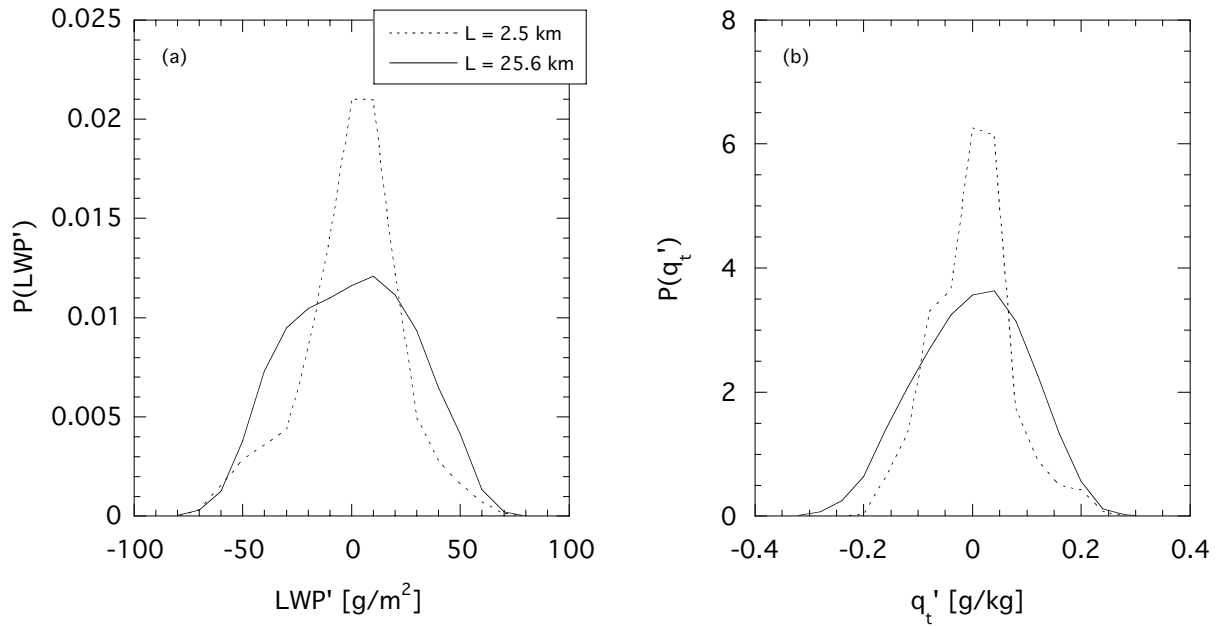

Figure 12. The probability density function $P$ for fluctuations of (a) the liquid-water path and (b) the total specific humidity in the middle of the cloud layer at $08 \mathrm{~h}$ local time. The two lines represent results from largeeddy simulations on the small $\left(2.5 \times 2.5 \mathrm{~km}^{2}\right)$ and large $\left(25.6 \times 25.6 \mathrm{~km}^{2}\right)$ horizontal domains. 
layer. De Roode et al. (2004) find that, although a small domain size may be sufficient to represent the vertical motions that have a spectral peak at scales on the order of the boundary-layer depth, this is not necessarily the case for quantities like the total specific humidity, for which fluctuations tend to grow at much larger scales. If these fluctuations cannot be properly represented by too small a domain, the variance of the quantity will be underestimated. For the PDFs shown in Fig. 12(b), the $q_{\mathrm{t}}$ variance is about a factor of two smaller in the small domain simulation, whereas the LWP variance is 812 and $514\left(\mathrm{~g} \mathrm{~m}^{-2}\right)^{2}$ for the large and small domain simulations, respectively.

Los and Duynkerke (2001) investigated the effect of horizontal cloud inhomogeneities on the mean albedo using the Independent Pixel Approximation. They applied a Taylor expansion to conclude that the albedo bias is mainly determined by the variance of the cloud optical depth. This implies that, given the same mean value for the LWP, a larger variance for the LWP will effectively lead to a reduction of the mean albedo.

\section{ENTRAINMENT}

The entrainment rates from the LES models shown in Fig. 13 were diagnosed by applying the tendency equation (10) for the boundary layer depth $z_{\mathrm{i}}$. The inversion height $z_{\mathrm{i}}$ is determined from the level where $q_{\mathrm{t}}=8.1 \mathrm{~g} \mathrm{~kg}^{-1}$, obtained by linear interpolation between adjacent grid levels of total water content. Figure 13 shows that there is a clear diurnal cycle in the entrainment rate. Minimum values are found for the daytime period when the buoyancy flux is minimal, and the mean entrainment rate from the six LES results is $w_{\mathrm{e}}=0.36 \pm 0.03 \mathrm{~cm} \mathrm{~s}^{-1}$, for 11 to $14 \mathrm{~h} \mathrm{LT}$. During night-time ( 01 to $04 \mathrm{~h} \mathrm{LT}$ ), the mean entrainment rate is larger, $w_{\mathrm{e}}=0.58 \pm 0.08 \mathrm{~cm} \mathrm{~s}^{-1}$.

A mixed-layer model was utilized to compute the budgets for heat and moisture during the night (Nicholls 1984). This model assumes that in the boundary layer the tendency for $\overline{\theta_{1}}$ does not depend on the height and is given by

$$
\frac{\partial \overline{\theta_{1}}}{\partial t}=\frac{w_{\mathrm{e}} \Delta \overline{\theta_{1}}+\overline{w^{\prime} \theta_{10}^{\prime}}}{z_{\mathrm{i}}}+\left\langle\frac{\partial \overline{\theta_{1}}}{\partial t}\right\rangle_{\mathrm{LS}}+\left\langle S_{\theta_{1}}\right\rangle,
$$

where the operator \langle\rangle gives the vertical mean value for any arbitrary function $f(z)$,

$$
\langle f\rangle=\frac{1}{z_{\mathrm{i}}} \int_{0}^{z_{\mathrm{i}}} f(z) \mathrm{d} z
$$

and $S_{\theta_{1}}$ is a source term that can represent, for example, the tendency due to a physical process like radiation. The tendency for the total water content is computed in a similar fashion to (11). If a different heating rate occurs in the sub-cloud layer than in the cloud layer, a situation typically encountered in a decoupled boundary layer during daytime, the mixed-layer model cannot be applied. The LS forcings like horizontal advection and the long-wave radiative flux divergence were computed in accordance with the case setup, (4) and (5). The LES results were used as input for the turbulent fluxes at the surface and for the entrainment rate at the boundary-layer top. From all the LES model results, we computed mean values representative for the night-time period, 01-04 h LT. For the turbulent surface fluxes of heat and moisture, we obtained $H=9.5 \pm 6.4 \mathrm{~W} \mathrm{~m}^{-2}$, $L E=31.7 \pm 5.1 \mathrm{~W} \mathrm{~m}^{-2}$.

The results presented in Table 5 indicate that entrainment causes the largest tendencies for both moisture and heat. Note that, although the long-wave radiative flux divergence causes a significant cooling, the application of (5) gives about the same 


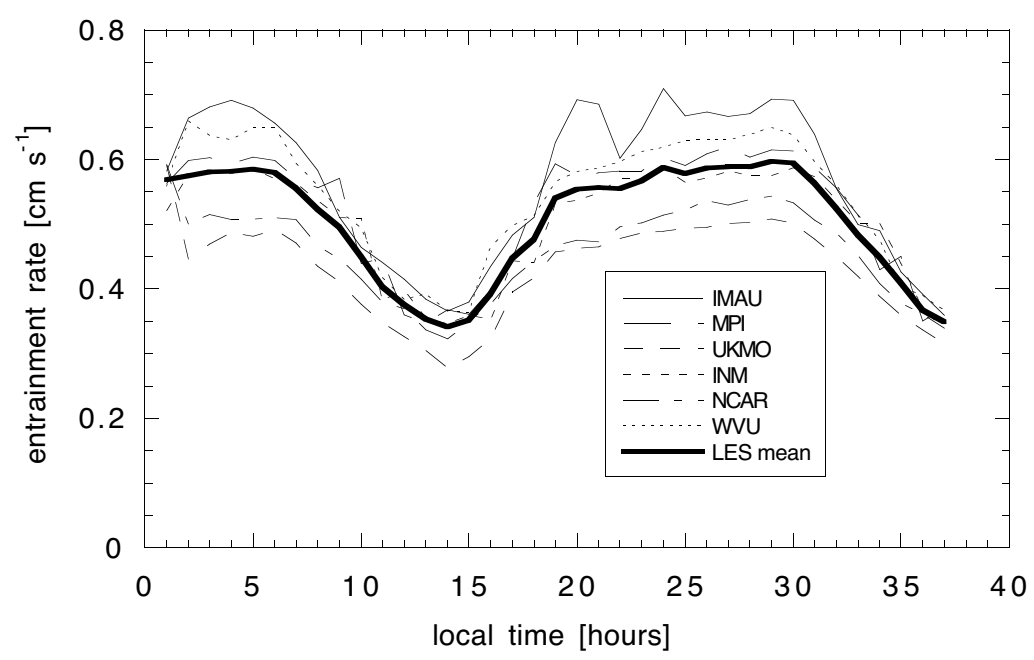

Figure 13. Entrainment rate as a function of time from six large-eddy simulations, plus the mean from all simulations.

TABLE 5. CONTRIBUTION OF THE SURFACE FLUXES, ENTRAINMENT, LARGE-SCALE HORIZONTAL ADVECTION AND RADIATION TO THE TENDENCIES OF LIQUID-WATER POTENTIAL TEMPERATURE AND TOTAL SPECIFIC HUMIDITY

\begin{tabular}{llllr}
\hline & \multicolumn{2}{c}{$\partial \bar{\theta}_{\mathrm{l}} / \partial t\left(\mathrm{~K} \mathrm{~h}^{-1}\right)$} & \multicolumn{2}{c}{$\partial \bar{q}_{\mathrm{t}} / \partial t\left(\mathrm{~g} \mathrm{~kg}^{-1} \mathrm{~h}^{-1}\right)$} \\
\hline Surface flux & $\bar{w}^{\prime} \theta_{0} / z_{\mathrm{i}}$ & $0.05 \pm 0.03$ & $\overline{w^{\prime} q^{\prime}}{ }_{0} / z_{\mathrm{i}}$ & $0.067 \pm 0.011$ \\
Entrainment flux & $w_{\mathrm{e}} \Delta \bar{\theta}_{\mathrm{l}} / z_{\mathrm{i}}$ & $0.42 \pm 0.06$ & $w_{\mathrm{e}} \Delta \bar{q}_{\mathrm{t}} / z_{\mathrm{i}}$ & $-0.105 \pm 0.015$ \\
Large-scale advection & $\left(\partial \bar{\theta}_{\mathrm{l}} / \partial t\right)_{\mathrm{LS}}$ & -0.14 & $\left(\partial \bar{q}_{\mathrm{t}} / \partial t\right)_{\mathrm{LS}}$ & 0.055 \\
Long-wave radiation & $\Delta F_{\mathrm{L}, \mathrm{tot}} /\left(\rho_{0} c_{p} z_{\mathrm{i}}\right)$ & -0.37 & & \\
\hline
\end{tabular}

The mean and standard error for the surface fluxes, entrainment rate, inversion height and inversion jumps were computed from all the LES results during the night-time period 01 to $04 \mathrm{~h}$ local time.

cooling rate for all LES models since the stratocumulus cloud layers are sufficiently optically thick during the entire diurnal cycle. Thus, we conclude that the differences in the entrainment rate among the LES models are the primary source for the variations in the simulated LWP evolution during night-time. During the night, a larger entrainment rate causes smaller LWPs, and vice versa.

A selection of observed entrainment rates is presented in Table 6. Kawa and Pearson $\mathrm{Jr}$ (1989) analysed aircraft observations collected during daytime in stratocumulus off the Southern California coast as part of the Dynamics and Chemistry of the Marine Stratocumulus (DYCOMS) experiment. They computed entrainment rates in the range $0.1-0.5 \mathrm{~cm} \mathrm{~s}^{-1}$, with an average value $w_{\mathrm{e}}=0.30 \pm 0.11 \mathrm{~cm} \mathrm{~s}^{-1}$. The LES results of the entrainment rate during daytime fall within the range of these observed entrainment rates.

As part of DYCOMS II, aircraft observations were collected $500 \mathrm{~km}$ west-southwest of San Diego, California. Stevens et al. (2003) used night-time observations collected on 10 July 2001 to compute an average entrainment rate of $w_{\mathrm{e}}=0.4 \pm$ $0.1 \mathrm{~cm} \mathrm{~s}^{-1}$. Figure 3 shows that the rather dry free atmosphere makes the DYCOMS II case unstable with respect to the cloud-top entrainment instability criterion (Randall 1980; Deardorff 1980). If a stratocumulus cloud layer is unstable according to this criterion, this may lead to a rapid break-up of the cloud due to enhanced entrainment 
TABLE 6. INVERSION JUMP PROPERTIES, CLOUD-BASE $\left(z_{\mathrm{cb}}\right)$ AND CLOUD-TOP $\left(z_{\mathrm{ct}}\right)$ HEIGHTS, AND ENTRAINMENT RATES $\left(w_{\mathrm{e}}\right)$ AS OBSERVED IN STRATOCUMULUS-TOPPED BOUNDARY LAYERS

\begin{tabular}{llccrccc}
\hline Case & \multicolumn{1}{c}{ Flight } & $\begin{array}{c}\Delta q_{\mathrm{t}} \\
\left(\mathrm{g} \mathrm{kg}^{-1}\right)\end{array}$ & $\begin{array}{c}\Delta \theta_{\mathrm{l}} \\
(\mathrm{K})\end{array}$ & $\begin{array}{r}z_{\mathrm{cb}} \\
(\mathrm{m})\end{array}$ & $\begin{array}{c}z_{\mathrm{ct}} \\
(\mathrm{m})\end{array}$ & $\begin{array}{c}w_{\mathrm{e}} \\
\left(\mathrm{cm} \mathrm{s}^{-1}\right)\end{array}$ & $\begin{array}{c}w_{\mathrm{e}}(\mathrm{LES}) \\
\left(\mathrm{cm} \mathrm{s}^{-1}\right)\end{array}$ \\
\hline North Sea & 511 & -3.0 & 8.4 & 1000 & 1320 & 0.50 & \\
& 526 & -2.1 & 7.4 & 380 & 830 & 0.71 & \\
& 528 & -4.7 & 8.9 & 1070 & 1260 & 0.24 & \\
& 620 & -3.0 & 9.2 & 960 & 1300 & 0.44 & \\
ASTEX & 624 & -3.6 & 9.8 & 580 & 1120 & 0.56 & \\
& 1 & -1.8 & 4.3 & 250 & 740 & $0.25 \pm 0.15$ & \\
& 2 & -1.2 & 6.2 & 240 & 755 & $1.1 \pm 0.5$ & $1.2 \pm 0.3$ \\
DYCOMS & 1-10 & -0.9 & 5.1 & 280 & 770 & $1.2 \pm 1.0$ & $1.9 \pm 0.1$ \\
DYCOMS II & RF01 & -4.3 & 5.8 & 610 & 1070 & $0.85 \pm 0.53$ & \\
FIRE & July 14 & -3.0 & 10.0 & 600 & 840 & $0.4 \pm 0.1$ & 0.38 \\
\hline FIRE & IMAU LES & -3.0 & 12.0 & 233 & 560 & & $0.58 \pm 0.08$ \\
FIRE Exp 1 & IMAU LES & -1.0 & 12.0 & 230 & 591 & & 0.68 \\
FIRE Exp 2 & IMAU LES & -5.0 & 12.0 & 395 & 582 & & 0.77 \\
FIRE Exp 3 & IMAU LES & -3.0 & 9.0 & 313 & 627 & & 0.64 \\
\hline
\end{tabular}

The observations are described in detail by Nicholls and Leighton (1986) (North Sea), De Roode and Duynkerke (1997) (ASTEX), Kawa and Pearson Jr (1989) (DYCOMS), and Stevens et al. (2003) (DYCOMS II), In DYCOMS the cloud layer was typically 150 to $300 \mathrm{~m}$ deep. For FIRE, the jump conditions are from Eq. (1), and $z_{\mathrm{cb}}$ and $z_{\mathrm{ct}}$ represent mean night-time values observed between 01 and $04 \mathrm{~h} \mathrm{LT}$. In addition, entrainment rates from large-eddy simulations are shown. ASTEX Flight 2 was simulated by seven different LES models as part of a GCSS Working Group 1 intercomparison study. The LES of ASTEX Flight 3 by four different models is discussed by Duynkerke et al. (1999). The DYCOMS II case was simulated with the NCAR LES model. $\Rightarrow$ indicates the typical range during the DYCOMS flights.

fluxes of heat and moisture. Obviously, the DYCOMS II observations violate this hypothesis, since the cloud layer was found to thicken during the night. It is also remarkable that the entrainment rate for the DYCOMS II case is smaller than the entrainment rate from LES models for FIRE, contradicting the expectation that the unstable jump conditions will be accompanied by larger entrainment rates.

Chlond and Wolkau (2000) quantified the uncertainty raised from the incomplete knowledge of the environmental parameters that are required to specify the initial and boundary conditions of a particular case-study. They explained that, in particular, uncertainties in the cloud-top jump of total water mixing ratio and the net radiative forcing explain most of the variation of LES solutions. Therefore, additional LESs were performed with the IMAU and MPI models to study the effect of changes in the inversion jumps on the cloud evolution. If the $\Delta \theta_{1}$ jump is decreased by $3 \mathrm{~K}$ compared with the reference case (for more details see FIRE Exp 3 in Table 6, and Fig. 3 for the inversion jumps), this results in a significant increase of the entrainment rate. Note that, despite the much larger entrainment rate for Exp 3, the cloud-layer depth during the first four hours of this simulation is only a fraction smaller than that of the reference case. In contrast, Table 6 shows that modifying the initial moisture jump across the inversion (Exp 1 and 2) has a pronounced effect on the cloud-layer depth evolution, although the entrainment rate does not change very much in comparison to the reference case. A more detailed discussion of sensitivity tests performed with the MPI LES model can be found in Chlond et al. (2004).

Entrainment rates of the order of $\sim 1 \mathrm{~cm} \mathrm{~s}^{-1}$ were found from observations collected during ASTEX (De Roode and Duynkerke 1997). Flight 3 of the ASTEX First Lagrangian was used for a LES intercomparison study set up by Duynkerke et al. (1999). From four different LES models, a mean entrainment rate $w_{\mathrm{e}}=1.9 \pm 0.1 \mathrm{~cm} \mathrm{~s}^{-1}$ was 
found. Note that three of these models are discussed in this paper (IMAU, MPI, INM). Both the observations and LES results indicate larger entrainment rates than the Pacific stratocumulus cases. This is clearly due to much smaller $\Delta \theta_{1}$ jumps in the Atlantic stratocumulus cases than those over the Pacific.

\section{SUGGESTIONS FOR MODEL IMPROVEMENT}

During the EUROCS project, various paths have been explored to improve turbulent mixing in the stratocumulus-topped boundary layer, most of them being related to the mixing across the cloud top. Lock (2004) argues that an explicit parametrization for the entrainment rate results in improved simulations of stratocumulus cloud fields. In an SCM that utilizes an eddy diffusivity approach, the entrainment flux at the top of the cloud layer is computed as

$$
\left.\overline{w^{\prime} \chi^{\prime}}\right|_{z_{\mathrm{i}}}=-\left.K_{\chi}\right|_{z_{\mathrm{i}}} \frac{\left.\Delta \bar{\chi}\right|_{z_{\mathrm{i}}}}{\left.\Delta z\right|_{z_{\mathrm{i}}}},
$$

where the operator $\Delta \chi$ gives the vertical difference of $\chi$ between two adjacent grid levels. If the cloud layer is capped by a discontinuous inversion with jump properties $\left.\Delta \bar{\chi}\right|_{z_{\mathrm{i}}}$, the entrainment flux is, to a good approximation, given by

$$
\left.\overline{w^{\prime} \chi^{\prime}}\right|_{z_{\mathrm{i}}}=-\left.w_{\mathrm{e}} \Delta \bar{\chi}\right|_{z_{\mathrm{i}}} .
$$

This equation is exact only if the inversion layer is infinitesimally thin, but since the inversion layers capping stratocumulus have typical depths of the order of a few tens of metres, (14) is an appropriate assumption. Equations (13) and (14) are equivalent if (Beljaars and Betts 1992; Lock 1998; Grenier and Bretherton 2001)

$$
\left.K_{\chi}\right|_{z_{\mathrm{i}}}=\left.w_{\mathrm{e}} \Delta z\right|_{z_{\mathrm{i}}} .
$$

This expression provides a consistent means to include an entrainment rate parametrization in a first-order turbulence closure model.

Lenderink and Holtslag (2000) have demonstrated that a coarse vertical resolution can lead to a poor performance of so-called E-l turbulence models. To resolve this problem, Chlond et al. (2004) have incorporated a numerical front tracking/capturing method designed by Zhong et al. (1996), which allows the computation of propagating phase boundaries. The advantage of this formulation is that it permits the stratocumulus top to lie between vertical grid levels and continuously evolve with time, and there is no spurious numerical entrainment.

To improve vertical mixing in the (cloud-topped) boundary layer, Lenderink and Holtslag (2004) propose a modified length-scale formulation in terms of a vertical integral of the stability, to solve problems that arise when the local stability is defined by a Richardson number, for example, and to improve mixing near the surface.

The SCM sensitivity tests with the convection scheme switched either on or off indicate that it may be desirable to develop a single scheme to represent the clear convective boundary layer for both stratocumulus and cumulus (De Roode et al. 2000; Lappen and Randall 2001). Sánchez and Cuxart (2004) discuss a master length-scale that is based on Bougeault and Lacarrère (1989), and which is also applicable to cumulus-topped boundary layers. Cheinet and Teixeira (2003) suggest that an eddydiffusivity approach may be applied to cumulus convection as well, whereas Cheinet (2003) tests a multiple mass-flux approach in which clear and cloudy convective plumes are explicitly represented. 
The quality of simulations that apply an explicit entrainment rate parametrization such as (15) still depends on the accuracy of the entrainment rate parametrization itself. The scaling behaviour of entrainment is still not yet fully understood and remains a major challenge (Turton and Nicholls 1987; Lewellen and Lewellen 1998; Lock 1998; Van Zanten et al. 1999; Moeng 2000; Lilly 2002). The need for further improvement of entrainment parametrizations was demonstrated by Stevens (2002), who applied mixedlayer theory to synthesize and evaluate several existing entrainment parametrizations for the stratocumulus-topped boundary layer. His results illustrated that these entrainment parametrizations exhibit marked differences. Such differences imply differences of a factor of two in climatologically important properties such as the LWP and boundarylayer depth.

Entrainment rate parametrizations usually include a measure of the buoyancy forcing. Because the buoyancy flux in the STBL is generally not a linear function of height, one may consider its vertical integral or the convective velocity-scale (Grenier and Bretherton 2001),

$$
w_{*}=\left(2.5 \frac{g}{\theta_{0}} \int_{0}^{z_{\mathrm{i}}} \overline{w^{\prime} \theta_{\mathrm{v}}^{\prime}} \mathrm{d} z\right)^{1 / 3} .
$$

Scaling the entrainment rate in stratocumulus is complicated, not only because the buoyancy flux depends on the entrainment rate, but also since the number of free parameters that determine the vertical profile of the buoyancy flux is much larger than that for the dry convective boundary layer. In the latter case, the entrainment rate is proportional to the ratio of the surface buoyancy flux $\overline{w^{\prime} \theta_{\mathrm{v} 0}^{\prime}}$ and the buoyancy jump across the inversion $\Delta \theta_{\mathrm{v}}$. However, the total water flux gives a large contribution to the buoyancy flux in a stratocumulus cloud layer (Stevens 2002), which is due to the condensation and evaporation of liquid water droplets. For this reason, the surface moisture flux, the total specific humidity jump across the inversion, the cloud-base and cloud-top heights, and the long-wave radiative flux divergence at the cloud top are all relevant quantities. In summary, if we assume that the entrainment rate depends on the vertical profile of the buoyancy flux, a general scaling expression will depend on the following (conserved) quantities:

$$
w_{\mathrm{e}}=f\left\{\overline{w^{\prime} \theta_{\mathrm{v}}^{\prime}}(z)\right\}=f\left\{\overline{w^{\prime} \theta_{10}^{\prime}}, \overline{w^{\prime} q^{\prime}} 0, \Delta \theta_{\mathrm{l}}, \Delta q_{\mathrm{t}}, z_{\mathrm{cb}}, z_{\mathrm{ct}}, \Delta F_{\mathrm{L}, \text { tot }}\right\} .
$$

In addition, short-wave radiative absorption in the cloud layer during daytime, wind shear, and drizzle also affect the buoyancy flux profile. The sensitivity of the buoyancy flux to the quantities summarized above, and the role of the entrainment rate on the buoyancy flux vertical profile, can all be clearly illustrated by means of a mixedlayer model (Nicholls 1984). In this context it is interesting to note that Lewellen and Lewellen (2004) present approximate expressions for the buoyancy flux formulated in terms of the liquid-water potential temperature and total water profiles, and their respective flux profiles. The predictions compare favourably with the results of an extensive set of LESs, including this EUROCS stratocumulus case.

\section{CONCLUSIONS}

Results of numerical simulations of the EUROCS diurnal cycle of stratocumulus are discussed. In total, six Large-Eddy Simulation models and ten Single-Column Models participated in this study. The models were initialized on the basis of observations that were collected in stratocumulus off the coast of California during FIRE I, in July 1987. 
The LES results of the surface energy balance and the turbulence structure of the STBL during the diurnal cycle are compared with observations. The accuracy of the SCMs, which are taken from various general-circulation models, is assessed from a comparison of the modelling results with the observed cloud evolution and results from the LESs.

The observed diurnal cycle of stratocumulus is characterized by a cloud layer which gradually thickens during the night, whereas during the day the cloud layer thins due to short-wave radiative absorption and decoupling. The latter state is characterized by slightly negative buoyancy fluxes and a minimum vertical velocity variance near the cloud base. This implies that surface-driven, moist thermals cannot then penetrate the cloud layer, while entrainment maintains a steady supply of relatively warm and dry air from just above the inversion into the cloud layer. This results in a distinct diurnal cycle of the LWP, which has minimum values during the day. During the night the vertical velocity variance has one single peak near the middle of the boundary layer. The observed turbulence structure, and the LWP temporal evolution are consistently reproduced by all the LES models.

More than half of the participating SCMs predict cloud layers that are too thin, and in particular during the day about half of the models give a cloud cover less than unity. Consequently, in these models the downwelling short-wave radiation reaching the surface is much larger than is observed. Because the cloud-top height computed by the SCMs is found to be systematically lower compared with the observations and the LES results, it is likely that the entrainment rates in these SCMs are too low. In a GCM it is therefore vital that the entrainment rate in a STBL is parametrized accurately. Several suggestions have been made recently for improvements of parametrizations for the cloudy boundary layer based on this EUROCS stratocumulus case. Basically, model improvements are sought in terms of explicit entrainment parametrizations, a better representation of a sharp inversion in a vertically coarse resolution, modified length-scale formulations, and parametrizations that can be applied not only to the clear convective boundary layer and stratocumulus, but also to cumulus.

In order to determine the process that is most important for the boundary-layer temporal evolution, a mixed-layer analysis of the budgets of moisture and heat was performed. It is found that entrainment is the dominant process in modifying the thermodynamic state of the boundary layer during the night. The entrainment rates modelled by the different LES models appear fairly consistent, with typical variations in the LES entrainment rates of the order of $1 \mathrm{~mm} \mathrm{~s}^{-1}$. Such small differences are sufficient to cause significant deviations in the modelled LWP evolution and, consequently, in the net downwelling short-wave radiation during the day.

From a comparison between observations and results from LESs of stratocumulus over the Pacific (FIRE I, DYCOMS I, DYCOMS II) and the Atlantic Ocean (ASTEX), we found that the smallest entrainment rates are found for the Pacific cases. Typically, the observed inversion jumps of the liquid-water potential temperature were larger for the Pacific stratocumulus cases than for the Atlantic cases. The Pacific cases seem to have a rather persistent character, whereas the ASTEX First Lagrangian observed a transition from stratocumulus to cumulus penetrating thin and broken stratocumulus above. The entrainment rate observed in a persistent nocturnal STBL during DYCOMS II (Stevens et al. 2003) is found to be smaller than the mean entrainment rate obtained from the LESs of the FIRE I case for the night-time period, despite the fact that the DYCOMS II case has a less stable inversion stratification than the FIRE I case. This DYCOMS II case serves as a new GCSS working group 1 model intercomparison study, and it is expected that the entrainment rate in a stratocumulus layer which satisfies the cloud-top entrainment instability criterion proposed by Randall (1980) and 
Deardorff (1980) will be subject to further analysis. In addition, the role of drizzle will be explored.

It is found that, from an LES on a large horizontal domain, mesoscale fluctuations in the LWP field develop, which is in accord with frequent satellite observations of stratocumulus fields. An analysis of the probability density functions of the LWP and the total specific humidity shows that they are much broader for the larger-domain simulation. Because the mesoscale fluctuations tend to grow gradually with time (De Roode et al. 2004), they may not be of importance for simulations of relatively short time-scales (less than 3 hours), but for longer (such as diurnal) time-scales the spectral broadening in the liquid-water field may become relevant. Lastly, to study the effect of horizontal inhomogeneities of the LWP distribution, it is recommended that a much larger LES horizontal domain be used than a typical LES domain of, for example, $3 \times 3 \mathrm{~km}^{2}$ in the horizontal.

\section{ACKNOWLEDGEMENTS}

The investigations were supported by the European Project on Cloud Systems in Climate Models (EUROCS), contract EVK2-CT-1999-00051. M. C. van Zanten acknowledges the support received from National Science Foundation grant ATM0097053 and the Foundation for Fundamental Research on Matter. S. R. de Roode received support from the Netherlands Organization for Scientific Research. The supercomputer computations performed by M. C. van Zanten and S. R. de Roode were sponsored by the National Computing Facilities Foundation. D. Lewellen's research was supported by the US Office of Naval Research (Grant N00014-98-1-0595).

\section{APPENDIX}

\section{Delta-Eddington approximation for short-wave radiation}

The net short-wave radiation $F_{\mathrm{S}}$ is obtained from the analytical solution of the deltaEddington approximation. The delta-Eddington equations are exactly the same as the Eddington equations (Joseph et al. 1976) with transformed asymmetry factor $g$, singlescattering albedo $\omega$ and optical depth $\tau$ :

$$
\left.\begin{array}{rl}
g^{\prime} & =\frac{g}{1+g}, \\
\omega^{\prime} & =\frac{\left(1-g^{2}\right) \omega}{1-\omega g^{2}}, \\
\tau^{\prime} & =\left(1-\omega g^{2}\right) \tau .
\end{array}\right\}
$$

If we assume $\omega$ and $g$ constant with height, an analytical solution for the Eddington approximation can be obtained (Shettle and Weinman 1970):

$$
F_{\mathrm{S}}(z)=\frac{4}{3} F_{0}\left[p\left\{C_{1} \mathrm{e}^{-k \tau(z)}-C_{2} \mathrm{e}^{k \tau(z)}\right\}-\beta \mathrm{e}^{-\tau(z) / \mu_{0}}\right]+\mu_{0} F_{0} \mathrm{e}^{-\tau(z) / \mu_{0}}
$$

with

$$
\left.\begin{array}{ll}
k=\{3(1-\omega)(1-\omega g)\}^{1 / 2}, & \alpha=3 \omega \mu_{0}^{2} \frac{1+g(1-\omega)}{4\left(1-k^{2} \mu_{0}^{2}\right)}, \\
p=\left\{\frac{3(1-\omega)}{1-\omega g}\right\}^{1 / 2}, & \beta=3 \omega \mu_{0} \frac{1+3 g(1-\omega) \mu_{0}^{2}}{4\left(1-k^{2} \mu_{0}^{2}\right)},
\end{array}\right\}
$$




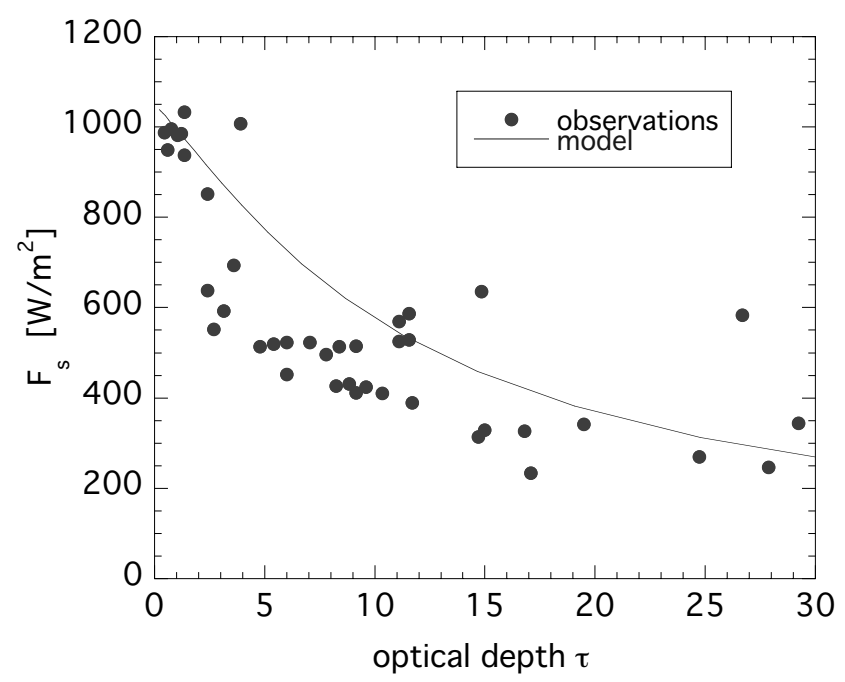

Figure A.1. The downward short-wave irradiance around solar noon $\left(\mu_{0}=0.95\right)$ at the surface as a function of optical depth: observations on San Nicolas Island (dots) and model calculations (line).

TABLE A.1. LIQUID-WATER POTENTIAL TEMPERATURE AND TOTAL WATER CONTENT AS A FUNCTION OF HEIGHT FOR RADIATION CALCULATIONS IN THE TROPOSPHERE

\begin{tabular}{rcc}
\hline$z(\mathrm{~m})$ & $\theta_{\mathrm{l}}(\mathrm{K})$ & $q_{\mathrm{t}}\left(\mathrm{g} \mathrm{kg}^{-1}\right)$ \\
\hline 0 & 287.50 & 9.60 \\
595 & 287.50 & 9.60 \\
605 & 299.50 & 6.60 \\
2095 & 310.75 & 2.10 \\
3153 & 317.29 & 1.481 \\
5900 & 326.75 & 0.379 \\
7600 & 329.28 & 0.098 \\
9670 & 336.61 & 0.020 \\
\hline
\end{tabular}

and $F_{0}=1100 \mathrm{~W} \mathrm{~m}^{-2}$ the downward solar radiation at cloud top. According to microphysical observations during FIRE I discussed by Duda et al. (1991), we prescribe the effective radius, $r_{\mathrm{eff}}=10 \mu \mathrm{m}$. The values of the constants $C_{1}$ and $C_{2}$ in (A.2) are determined from the boundary condition at the surface (albedo $A_{\text {sfc }}=0.05$ ) and above the cloud. (See Shettle and Weinman (1970) for further details.)

From the observed liquid-water path on San Nicolas Island, we have calculated the optical depth from (7) with $r_{\text {eff }}=10 \mu \mathrm{m}$. In Fig. A.1 we have plotted the measured downward short-wave radiative flux as a function of the calculated optical depth for observations around local noon. Moreover, we have shown the model results for $\mu_{0}=\cos \theta_{0}=0.95$, which give somewhat higher values than the observations. This may possibly be explained by the fact that the observed clouds are horizontally inhomogeneous as opposed to what is assumed in the delta-Eddington method, or a systematic bias in the observed cloud optical depth.

LES and SCM models that do not use the suggested radiation codes may need a temperature and humidity profile above $1200 \mathrm{~m}$ for the radiation calculations. Table A.1 gives some typical numbers that were derived from radiosonde stations along the Californian coast. If values at intermediate levels are needed they can be obtained by linear interpolation. 
Albrecht, B. A., Fairall, C. W., Thomson, D. W., White, A. B., Snider, J. B. and

Schubert, W. H.

Albrecht, B. A., Randall, D. A. and Nicholls, S.

Beljaars, A. C. M. and Betts, A. K.

Betts, A. K.

Blaskovic, M., Davies, R. and Snider, J. B.

Bougeault, P. and Lacarrère, P.

Bretherton, C. S., Krueger, S. K., Wyant, M. C., Bechtold, P., Meijgaard, E. V., Stevens, B. and Teixeira, J.

Bretherton, C. S., Uttal, T., Fairall, C. W., Yuter, S., Weller, R., Baumgardner, D., Comstock, K., Wood, R. and Raga, G.

Brown, A. R.

Brown, A. R., Cederwall, R. T., Chlond, A., Duynkerke, P. G., Golaz, J.-C.,

Khairoutdinov, M., Lewellen, D. C., Lock, A. P., Macvean, M. K.,

Moeng, C.-H.,

Neggers, R. A. J.,

Siebesma, A. P. and

Stevens, B.

Cahalan, R. F. and Snider, J. B.

Cahalan, R. F., Ridgway, W., Wiscombe, W. J., Gollmer, S. and Harshvardhan

Cheinet, $\mathrm{S}$.

1990

1988

1992

1990

1991

1989

1999

2004

1999

2002

1989

1994

2002

2003

Cheinet, S. and Teixeira. J.

2003

Chlond, A. and Wolkau, A.

2000

Chlond, A., Müller, F. and Sednev, I.

De Roode, S. R. and Duynkerke, P. G.

De Roode, S. R., Duynkerke, P. G. and Siebesma, A. P.

De Roode, S. R., Duynkerke, P. G. 2004 and Jonker, H. J. J.

Deardorff, J. W.

\section{REFERENCES}

Surface-based remote sensing of the observed and the adiabatic liquid-water content of stratocumulus clouds. Geophys. Res. Lett., 17, 89-92

Observations of marine stratocumulus clouds during FIRE. Bull. Am. Meteorol. Soc., 69, 618-626

'Validation of the boundary layer representation in the ECMWF model'. In proceedings of seminar on Validation of models over Europe, ECMWF, Reading, UK

The diurnal variation of California coastal stratocumulus for two days of boundary layer soundings. Tellus, 42A, 302-304

Diurnal variation of marine stratocumulus over San Nicolas Island during July 1987. Mon. Weather Rev., 119, 1469-1478

Parameterization of orography-induced turbulence in a mesobetascale model. Mon. Weather Rev., 117, 1872-1890

A GCSS boundary-layer cloud model intercomparison study of the first ASTEX Lagrangian experiment. Boundary-Layer Meteorol., 93, 341-380

The EPIC 2001 stratocumulus study. Bull. Amer. Meteorol. Soc., 85, 967-977

The sensitivity of large-eddy simulations of shallow cumulus convection to resolution and subgrid model. Q. J. R. Meteorol. Soc., 125, 469-482

Large-eddy simulation of the diurnal cycle of shallow cumulus convection over land. Q. J. R. Meteorol. Soc., 128, 10751093

Marine stratocumulus structure. Remote Sensing Environ., 28, 95-107

Independent pixel and Monte-Carlo estimates of stratocumulus albedo. J. Atmos. Sci., 51, 3776-3790

'The parameterization of clear and cloudy convective boundary layers'. Ph.D. thesis, École Polytechnique, Paris, France

A multiple mass-flux parameterization for the surface generated convection. part 1: Dry plumes. J. Atmos. Sci., 60, 23132327

A simple formulation for the eddy-diffusivity parameterization of cloud-topped boundary layers. Geophys. Res. Lett., 30, doi: 10.1029/2003GL017377

Large-eddy simulation of a nocturnal stratocumulus-topped marine atmospheric boundary layer: An uncertainty analysis. Boundary-Layer Meteorol., 95, 31-55

2004 Numerical simulation of the diurnal cycle of marine stratocumulus during FIRE-An LES and SCM modelling study. Q. J. R. Meteorol. Soc., 130, 3297-3321

1997 Observed Lagrangian transition of stratocumulus into cumulus during ASTEX: Mean state and turbulence structure. J. Atmos. Sci., 54, 2157-2173

2000 Analogies between mass-flux and Reynolds-averaged equations. J. Atmos. Sci., 57, 1585-1598

Large-eddy simulation: How large is large enough? J. Atmos. Sci., 61, 403-421

1980 Cloud-top entrainment instability. J. Atmos. Sci., 37, 131-147 
Duda, D. P., Stephens, G. L. and Cox, S. K.

Duynkerke, P. G. and Hignett, P.

Duynkerke, P. G. and Teixeira, J.

2001

Duynkerke, P. G., Jonker, P. J., Chlond, A., Van Zanten, M. C., Cuxart, J., Clark, P., Sánchez, E., Martin, G. M., Lenderink, G. and Teixeira, J Grenier, H. and Bretherton, C. S.

Guichard, F., Petch, J. C., Redelsperger, J.-L., Bechtold, P., Chaboureau, J.-P., Cheinet, S., Grabowski, W., Grenier, H., Jones, C. G., Köhler, M., Pirou, J.-M., Tailleux, R. and Tomasini, $\mathrm{M}$.

Hignett, P.

Hogg, D. C., Guiraud, F. O., Snider, J. B., Decker, M. T. and Westwater, E. R.

Jakob, C.

Joseph, J. H., Wiscombe, W. J. and Weinman, J. A.

Kawa, S. R. and Pearson Jr., R.

Klein, S. A. and Hartmann, D. L.

Kuo, H. and Schubert, W. H.

Lappen, C. L. and Randall, D. A.

Lenderink, G. and

Holtslag, A. A. M.

Lenderink, G., Siebesma, A. P., Cheinet, S., Irons, S., Jones, C. G., Marquet, P., Müller, F., Olmeda, D., Calvo, J., Sánchez, E. and Soares, P. M. M.

Lewellen, D. C. and

Lewellen, W. S.

Lilly, D.

Lock, A. P.

Los, A. and Duynkerke, P. G.
Microphysical and radiative properties of marine stratocumulus from tethered balloon measurements. J. Appl. Meteorol., 30, $170-186$

Simutation of diurnal variation in a stratocumulus-capped marine boundary layer during FIRE. Mon. Weather Rev., 121, 32913300

Comparison of the ECMWF reanalysis with FIRE I observations: Diurnal variation of marine stratocumulus. J. Climate, 14, 1466-1478

Intercomparison of three- and one-dimensional model simulations and aircraft observations of stratocumulus. Boundary-Layer Meteorol., 92, 453-487

A moist PBL parameterization for large-scale models and its application to subtropical cloud-topped marine boundary layers. Mon. Weather Rev., 129, 357-377

Modelling the diurnal cycle of deep precipitating convection over land with cloud-resolving models and single column models. Q. J. R. Meteorol. Soc., 130, 3139-3172

Observations of the diurnal variation in a cloud-capped marine boundary layer. J. Atmos. Sci., 48, 1474-1482

1983 A steerable dual-channel microwave radiometer for measurements of water vapor and liquid in the troposphere. J. Clim. Appl. Meteorol., 22, 789-806

Clouds in the ECMWF re-analysis. J. Climate, 12, 947-959

The delta-Eddington approximation for radiative flux transfer. J. Atmos. Sci., 33, 2452-2459

An observational study of stratocumulus entrainment and thermodynamics. J. Atmos. Sci., 46, 2650-2661

The seasonal cycle of low stratiform clouds. J. Climate, 15871606

Stability of cloud-topped boundary layers. Q. J. R. Meteorol. Soc., 114, 887-917

Toward a unified parameterization of the boundary layer and moist convection. Part I: A new type of mass-flux model. J. Atmos. Sci., 58, 2021-2036

Evaluation of the kinetic energy approach for modelling turbulent fluxes in stratocumulus. Mon. Weather Rev., 128, 244-258

An updated length-scale formulation for turbulent mixing in clear and cloudy boundary layers. Q. J. R. Meteorol. Soc., 130, 3405-3427

The điurnal cycle of shallow cumulus clouds over land: A singlecolumn model intercomparison study. Q. J. R. Meteorol. Soc., 130, 3339-3364
1998

2004

2002

(1)

Large eddy boundary layer entrainment. J. Atmos. Sci., 55, 26452665

Buoyancy flux modeling for cloudy boundary layers. J. Atmos. Sci., 61, 1147-1160

Entrainment into cloud-topped mixed layers: A new closure. J. Atmos. Sci., 59, 3353-3361

The parametrization of entrainment in cloudy boundary layers. Q. J. R. Meteorol. Soc., 124, 2729-2753

The sensitivity of a GCM's marine stratocumulus to cloud-top entrainment. Q. J. R. Meteorol. Soc., submitted for the EUROCS special issue

2001 Parametrization of solar radiation in inhomogeneous stratocumulus: Albedo bias. Q. J. R. Meteorol. Soc., 127, 1593-1614 
Ma, C.-C., Mechoso, C. R., Robertson, A. W. and Arakawa, A.

Miller, R. L.

Moeng, C.-H.

Moeng, C.-H., Cotton, W. R., Bretherton, C. S., Chlond, A., Khairoutdinov, M.,

Krueger, S., Lewellen, W. S., MacVean, M. K.,

Pasquier, J. R. M.,

Rand, H. A., Siebesma, A. P., Stevens, B. and Sykes, R. I.

Moyer, K. A. and Young, G. S.

Neiburger, M.

Nicholls, S.

Nicholls, S. and Leighton, J.

Nigam, S.

Norris, J. R.

Philander, S. G. H., Gu, D., Halpern, D., Lambert, G., Lau, N.-C., Li, T. and Pacanowski, R. C.

Randall, D. A.

Sánchez, E. and Cuxart, J.

Schubert, W. H., Cox, S. K., Ciesielski, P. E. and Johnson-Pasqua, C. M.

Shettle, E. P. and Weinman, J. A.

Siebesma, A. P., Bretherton, C. S., Brown, A., Chlond, A., Cuxart, J., Duynkerke, P. G., Jiang, H., Khairoutdinov, M., Lewellen, D., Moeng, C.-H., Sánchez, E., Stevens, B. and Stevens, D. E.

Siebesma, A. P., Jakob, C., Lenderink, G., Neggers, R. A. J., Teixeira, J., Van Meijgaard, E., Calvo, J., Chlond, A., Grenier, H., Jones, C., Köhler, M., Kitagawa, H., Marquet, P., Lock, A. P., Müller, F., Stevens, B.
1996 Peruvian stratus clouds and the tropical Pacific circulation: A coupled ocean-atmosphere GCM study. J. Climate, 9, 1635-1645

1997 Tropical thermostats and low cloud cover. J. Climate, 10, 409-440

2000 Entrainment rate, cloud fraction and liquid-water path of PBL stratocumulus clouds. J. Atmos. Sci., 57, 3627-3643

1996 Simulation of a stratocumulus-topped planetary boundary layer: Intercomparison among different numerical codes. Bull. Am. Meteorol. Soc., 77, 261-278

1994 Observations of mesoscale cellular convection from the marine stratocumulus phase of FIRE. Boundary-Layer Meteorol., 71, 109-133

1960 The relation of air mass structure to the field of motion over the eastern North Pacific 1-40

1984 The dynamics of stratocumulus: aircraft observations and comparisons with a mixed layer model. Q. J. R. Meteorol. Soc., 110, 783-820

1986 An observational study of the structure of stratiform cloud sheets: I. Structure. Q. J. R. Meteorol. Soc., 112, 431-460

1997 The annual warm to cold phase transition in the eastern equatorial pacific: Diagnosis of the role of stratus cloud-top cooling. J. Climate, 10, 2447-2467

1997a Low cloud type over the ocean from surface observations. Part I: Relationship to surface meteorology and the vertical distribution of temperature and moisture. J. Climate, 11, 369-382

1997b Low cloud type over the ocean from surface observations. Part II: Geographical and seasonal variations. J. Climate, 11, 383-403

1996 Why the ITCZ is mostly north of the equator. J. Climate, 9, 2958-2972

1980 Conditional instability of the first kind upside down. J. Atmos. Sci., 37, 125-130

2004 A buoyancy-based mixing-length proposal for cloudy boundary layers. Q. J. R. Meteorol. Soc., 130, 3385-3404

1987 'Operation of a ceilometer during the FIRE marine stratocumulus project.' Atmospheric Science Paper No. 420. Colorado State University, Fort Collins, CO, USA

1970 The transfer of solar irradiance through inhomogeneous turbid atmospheres evaluated by Eddington's approximation. J. Atmos. Sci., 27, 1048-1055

2003 A large eddy simulation intercomparison study of shallow cumulus convection. J. Atmos. Sci., 60, 1201-1219

2004 Cloud representation in general-circulation models over the northern Pacific Ocean: A EUROCS intercomparison study. Q. J. R. Meteorol. Soc., 130, 3245-3267

2002 Entrainment in stratocumulus-topped mixed layers. Q. J. $R$. Meteorol. Soc., 128, 2663-2690 
Stevens, B., Ackerman, A. S.,

Albrecht, B. A., Brown, A. R.,

Chlond, A., Cuxart, J.,

Duynkerke, P. G.,

Lewellen, D. C.,

MacVean, M. K.

Neggers, R. A. J., Sánchez, E.,

Siebesma, A. P. and

Stevens, D. E.

Stevens, B., Lenschow, D. H.,

Faloona, I., Moeng, C.-H.,

Lilly, D. K., Blomquist,B.,

Vali, G., Bandy, A.,

Campos, T., Gerber, H.,

Haimov, S., Morley, B. and

Thornton, D.

Turton, J. D. and Nicholls, S.

Van Zanten, M. C.,

Duynkerke, P. G. and

Cuijpers, J. W. M.

White, A. B.

Wood, R., Bretherton, C. S. and Hartmann, D. L.

Wood, R. and Field, P. R.

Yu, J.-Y. and Mechoso, C. R.

Zhong, X., Hou, T. Y. and LeFloch, P. G.
2001

Simulations of trade wind cumuli under a strong inversion. J. Atmos. Sci., 58, 1870-1891

On entrainment rates in nocturnal marine stratocumulus. Q. J. R. Meteorol. Soc., 129, 3469-3494

A study of the diurnal variation of stratocumulus using a multiple mixed layer model. Q. J. R. Meteorol. Soc., 113, 969-1009

1999 Entrainment parameterization in convective boundary layers. J. Atmos. Sci., 56, 813-828

1999 'Temperature and humidity structure parameters deduced from sodar and radar reflectivities: An analysis of data from the marine stratocumulus phase of FIRE'. Master's thesis, Department of Meteorology, Pennsylvania State University, University Park, PA 16802, USA

Diurnal cycle of liquid-water path over the subtropical and tropical oceans. Geophys. Res. Lett., 29, art. 2092, doi: 10.1029/2002GL015371

2000 Relationships between total water, condensed water, and cloud fraction in stratiform clouds examined using aircraft data. J. Atmos. Sci., 57, 1888-1905

1999 Links between annual variations of Peruvian stratocumulus clouds and of SST in the eastern equatorial Pacific. J. Climate, 12, 3305-3318

1996
Computational methods for propagating phase boundaries. J. Comput. Phys., 124, 192-216 